\title{
UCLA
}

\section{Recent Works}

\section{Title}

Fuelling the future: microbial engineering for the production of sustainable biofuels

\section{Permalink}

https://escholarship.org/uc/item/5754v083

Journal

Nature Reviews Microbiology, 14(5)

\section{Authors}

Liao, James C

Mi, Luo

Pontrelli, Sammy

et al.

\section{Publication Date}

2016-05-30

Peer reviewed 
Thermohaline circulation Large-scale ocean currents that result from water density gradients, which are under the control of temperature (thermo) and salinity (haline).
'Department of Chemical and Biomolecular Engineering, University of California, Los Angeles (UCLA). ${ }^{2}$ Institute of Genomics and Proteomics, UCLA, California 90095, USA. Correspondence to J.C.L. liaoj@ucla.edu

\title{
Fuelling the future: microbial engineering for the production of sustainable biofuels
}

\author{
James C. Liao ${ }^{1,2}$, Luo Mi', Sammy Pontrelli' and Shanshan Luo'
}

Abstract | Global climate change linked to the accumulation of greenhouse gases has caused concerns regarding the use of fossil fuels as the major energy source. To mitigate climate change while keeping energy supply sustainable, one solution is to rely on the ability of microorganisms to use renewable resources for biofuel synthesis. In this Review, we discuss how microorganisms can be explored for the production of next-generation biofuels, based on the ability of bacteria and fungi to use lignocellulose; through direct $\mathrm{CO}_{2}$ conversion by microalgae; using lithoautotrophs driven by solar electricity; or through the capacity of microorganisms to use methane generated from landfill. Furthermore, we discuss how to direct these substrates to the biosynthetic pathways of various fuel compounds and how to optimize biofuel production by engineering fuel pathways and central metabolism.

Over the past few decades, increasing atmospheric greenhouse gasses (GHGs), including $\mathrm{CO}_{2}$, methane $\left(\mathrm{CH}_{4}\right)$ and nitrous oxide $\left(\mathrm{N}_{2} \mathrm{O}\right)$, have been linked to global climate and environmental changes ${ }^{1,2}$, such as rising sea levels, weakening of thermohaline circulation and eradication of coral reef. The global $\mathrm{CO}_{2}$ release from fossil fuel usage is now approximately $7 \mathrm{Gt}$ of carbon per year ${ }^{3,4}$, and the atmospheric $\mathrm{CO}_{2}$ concentration is 400 parts per million (ppm). If the current upward trend continues, the $\mathrm{CO}_{2}$ release rate is likely to double by 2050 (REF. 3). Doubling the $\mathrm{CO}_{2}$ emission rate without remediation is expected to increase the $\mathrm{CO}_{2}$ concentration to $500 \mathrm{ppm}^{3}$, which would lead to a global warming of approximately $2^{\circ} \mathrm{C}$ above the level in 1900 (REF. 2). This level of temperature rise would increase the risk of disintegration of the West Antarctic Ice Sheet (WAIS) ${ }^{2}$, as well as other negative effects. Complete disintegration of the WAIS, even if it were to occur gradually, would cause a disruptive rise of sea level by 4-6 metres (REF. 2). Although these scenarios and the quantitative relationship between $\mathrm{CO}_{2}$ emission, atmospheric $\mathrm{CO}_{2}$ concentration, global temperature and effect are subject to uncertainty, the potential risk of adverse effects on society, economy and the environment is too large to ignore. If we are to avoid reaching the $2{ }^{\circ} \mathrm{C}$ threshold, there would need to be a substantial decrease in carbon emission from fossil fuel usage, the scale-up of renewable energy supplies and a decrease in energy demand, all within a timescale of decades.
Compared with other renewable energy forms, liquid biofuels are more compatible with current infrastructure and have a higher energy density (BOX 1), which provides a basis for their long-term roles in the future energy mix. Traditionally, biofuels are defined as fuels that are produced from biomass by either biological or non-biological processes, but this definition can be broadened to include fuels produced from other renewable resources, such as landfill gas and $\mathrm{CO}_{2}$, by biological processes. The most common biofuel today is ethanol that is derived from corn starch or cane sugar ${ }^{6,7}$. To generate bioethanol, atmospheric $\mathrm{CO}_{2}$ is fixed by plants to form carbohydrates, which are subsequently fermented by microorganisms, such as yeast cells. As the generation of bioethanol uses cane sugar or corn starch as substrates, it does not require an expensive biomass deconstruction step. However, to increase the effect of biofuels, the range of raw materials utilized for next-generation biofuels should be expanded, and biofuel production should ultimately utilize either substrates that result from a net increase in global $\mathrm{CO}_{2}$ fixation or carbon that is released as greenhouse gases. Furthermore, replacing fossil fuels with biofuels does not necessarily reduce $\mathrm{CO}_{2}$ emission, unless all collateral emissions are considered ${ }^{8}$. Therefore, the production of next-generation biofuels should also account for the emission caused by the use of land to grow and harvest biomass ${ }^{9}$, the effect of that land use on biodiversity ${ }^{10}$ and the additional manufacturing $\operatorname{costs}^{11}$. 
Lignocellulose

The major component of the plant cell wall, which consists of cellulose, hemicellulose and lignin.

Cellulolytic organisms Organisms that can digest cellulose.

\section{Lithoautotrophic}

Capable of using $\mathrm{CO}_{2}$ as the carbon source and inorganic compounds as reducing equivalents.

Methylotrophs Capable of utilizing reduced $\mathrm{C}_{1}$ compounds
One advantage of using microorganisms for the production of next-generation biofuels is the metabolic diversity of bacteria, fungi and microalgae, which enables the use of different substrates as the starting point for biofuel generation. This includes the ability of bacteria and fungi to utilize lignocellulose from wastes and energy crops, the ability of bacteria and microalgae to fix $\mathrm{CO}_{2}$ and the capacity of microorganisms to use methane from landfill or natural gas wells that would otherwise be flared. For example, plant-derived lignocellulose can be utilized by cellulolytic organisms, such as Clostridium thermocellum, or hydrolysed by fungal cellulases into substrates for microbial fermentation (FIG. 1a). As an alternative to lignocellulose, $\mathrm{CO}_{2}$ can be directly utilized by photosynthetic organisms, such as microalgae and cyanobacteria, or by lithoautotrophic organisms that can use energy that is derived from renewable sources (FIG. 1b,c). Finally, methane, which is a more potent greenhouse gas than $\mathrm{CO}_{2}$ (REF. 12), can be utilized by methanotrophs or, after activation to methanol, by methylotrophs (FIG. 1d).

The microbiological challenges in all of these processes are to improve the carbon assimilation pathways in microorganisms and then channel the metabolic flux of these pathways to produce a desirable product through various natural or designed pathways. In addition to ethanol, many other longer-chain alcohols, alkanes and fatty acid esters are desirable fuels because of their favourable properties for specific applications. However, although some of these compounds or their precursors can be produced from various metabolic pathways that naturally exist in microorganisms, these pathways often need to be optimized or redesigned to improve efficiency. Furthermore, the practical or theoretical yields (gram of product per gram of raw material) based on current pathways and the productivity (production rate per

\section{Box 1 | Justification for biofuel}

To keep energy supply sustainable while mitigating the $\mathrm{CO}_{2}$ problem, the ultimate energy source must come from the sun, which radiates 120,000 TW of energy to Earth. This is much larger than the total energy demand of humans, which is 13 TW currently ${ }^{161}$. Direct harvesting of solar energy using photovoltaic cells is one approach to harness solar energy and to avoid the accumulation of $\mathrm{CO}_{2}$. Another approach is to rely on photosynthetic $\mathrm{CO}_{2}$ fixation to produce biomass, which is then converted to liquid fuel. These two platforms are both clean and sustainable in principle, but both face substantial practical challenges. Although solar electricity is carbon free and efficient, electricity storage is a major hurdle to the widespread use of this approach. The energy density for common rechargeable lithium-ion batteries is approximately $1 \mathrm{MJ} \mathrm{kg}^{-1}$ (REF. 162) (with a theoretical limit around $\left.2 \mathrm{MJ} \mathrm{kg}^{-1}\right)^{163,164}$, which is more than one order of magnitude lower than that of liquid fuel (typically $27-47 \mathrm{MJ} \mathrm{kg}^{-1}$ ) (see the figure). The energy density consideration limits the use of solar electricity in transportation and other large-scale applications, and is a fundamental factor in favour of liquid biofuel that is derived from carbon recycled from the atmosphere (as opposed to fossil carbon). In addition, the manufacturing of batteries for electric vehicles needs to be considered when calculating $\mathrm{CO}_{2}$ emission over the battery life cycle, and in some cases this may be comparable to, or greater than, burning fossil fuel in vehicles with internal combustion engines ${ }^{165}$, even though electric vehicles have no tailpipe emissions.

Another major factor in favour of biomass-derived fuel is the abundance of biomass. Approximately 123 billion metric tons of $\mathrm{CO}_{2}$ are fixed annually by terrestrial plants through photosynthesis ${ }^{166}$. Of the biomass generated in the United States, approximately 500 million dry tons of forest and agricultural biomass is potentially available at a low price (US $\$ 60$ per dry ton or less ${ }^{167}$ in 2012). This estimate includes forest and agricultural-land lignocellulosic waste resources that are not currently being used. If large-scale cultivation of energy crops is implemented, it is estimated that the biomass available at this price will increase to 1.1-1.5 billion dry tons by 2030 (REF. 167). 1 billion dry tons of biomass produced annually in a sustainable manner is estimated to be sufficient to displace $30 \%$ of the present US petroleum consumption.

Given its abundance and regeneration rate, biomass is considered to be the only foreseeable sustainable source of liquid fuel available to humanity. However, to harness this chemical energy and to convert plant biomass into readily useable fuel molecules, we must overcome several challenges, including land, water and fertilizer usage, the life cycle carbon saving and competition with non-renewable fuels. Because of low yield in every step, even at $\$ 60$ per dry ton of biomass, the raw material cost for lignocellulosic biofuel can be more than $\$ 1$ per gallon, which is a substantial portion of the final fuel cost. Thus, the efficient utilization of the raw material in every step is crucial.
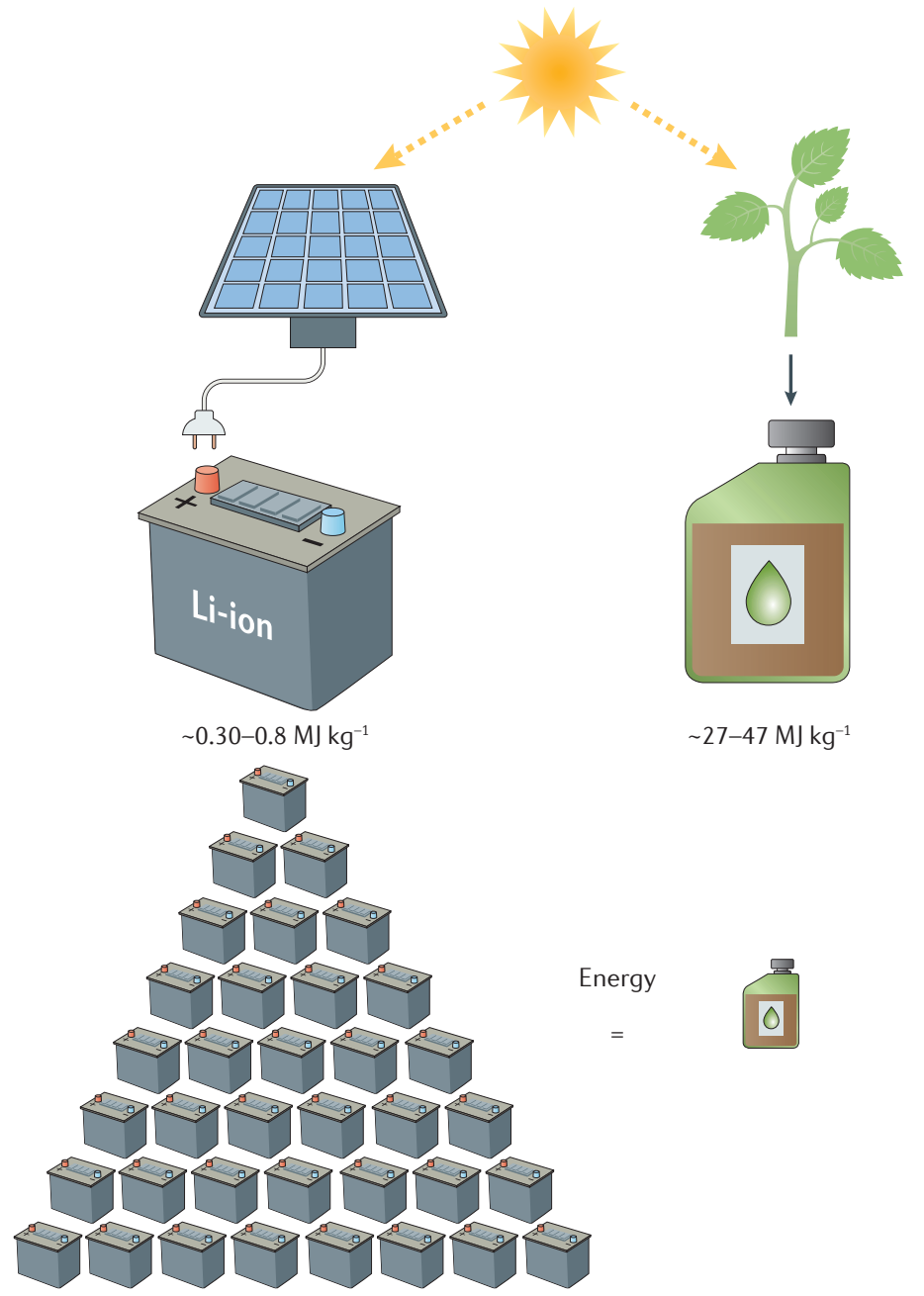


\section{REVIEWS}

a

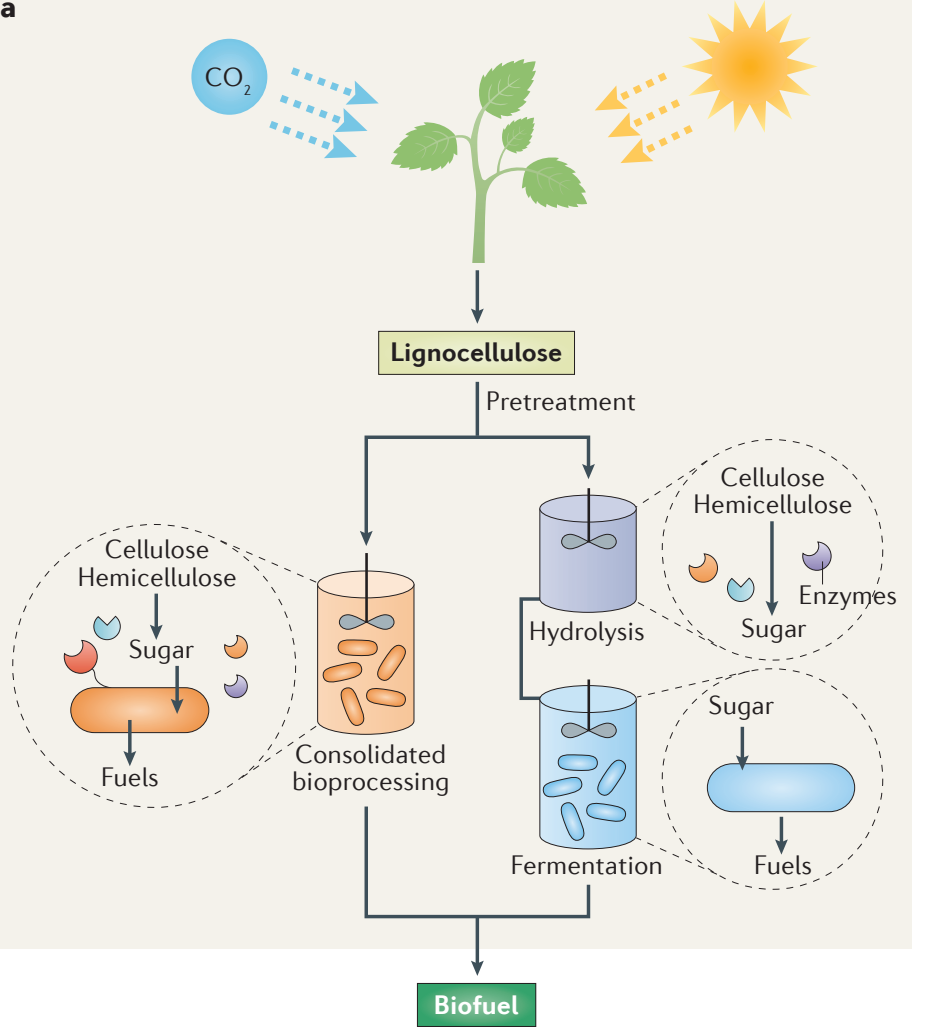

b

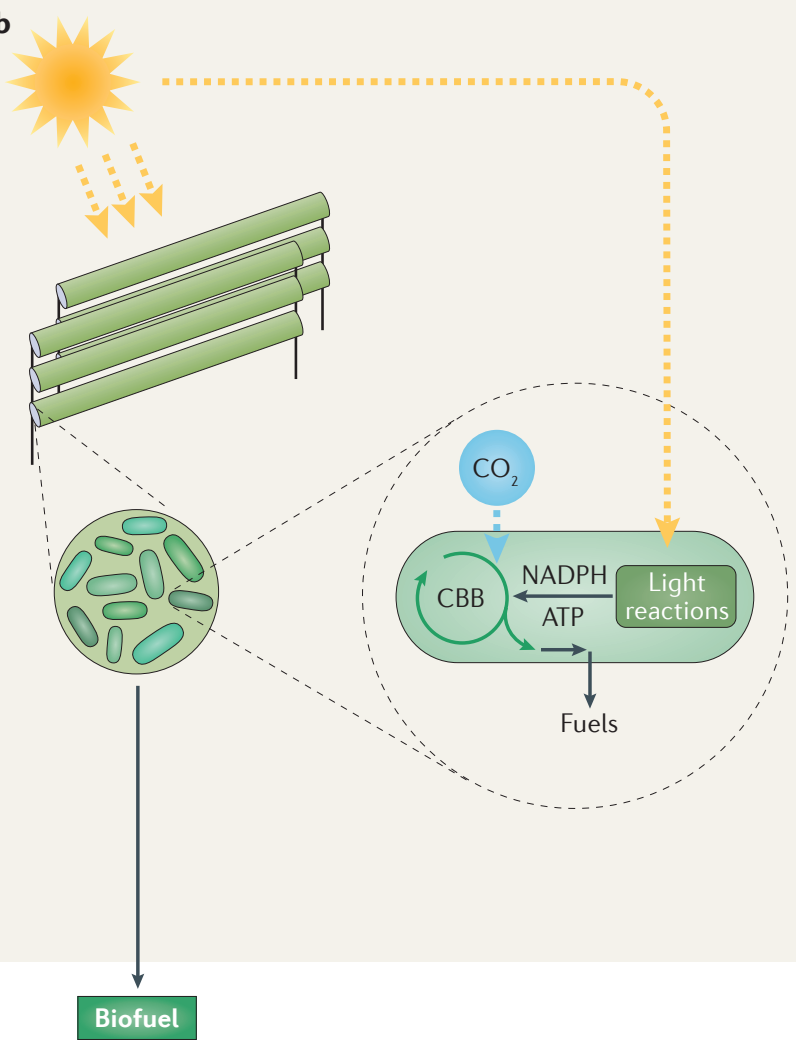

c

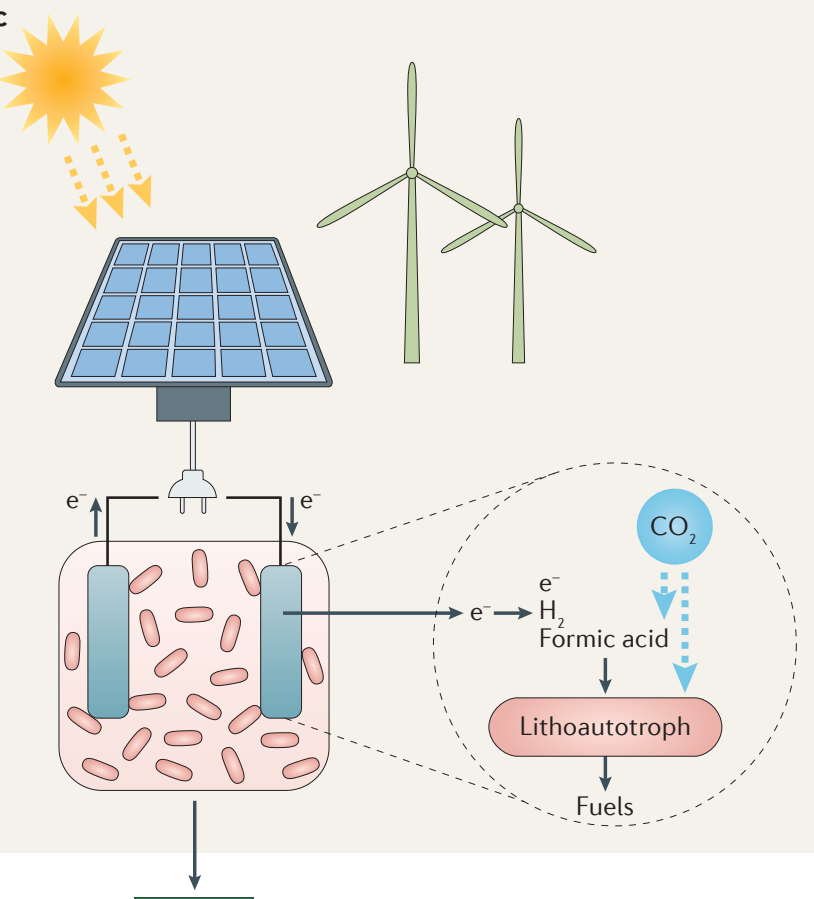

Biofuel d

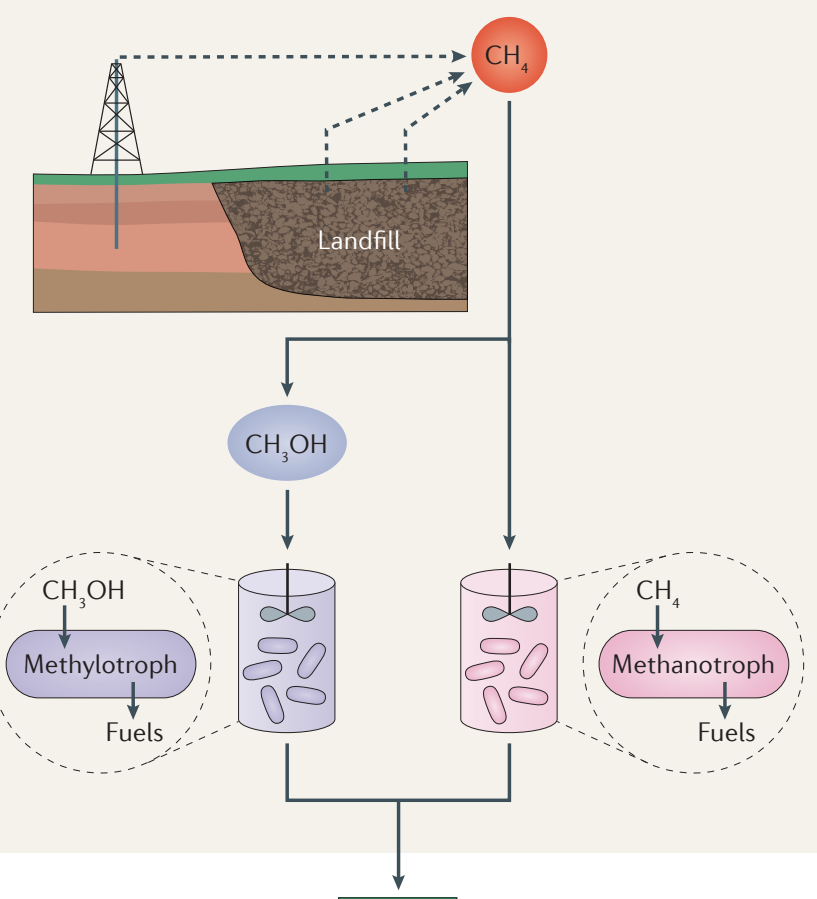

Biofuel

Figure 1 | Overview of biofuel production from sunlight and atmospheric carbon. a | The lignocellulose of plant biomass can be converted to fuels through hydrolysis followed by fermentation, or through consolidated bioprocessing, which combines the two processes in one reactor. $\mathbf{b} \mid$ Photosynthetic organisms, such as microalgae and cyanobacteria, can harness energy from sunlight to reduce $\mathrm{CO}_{2}$ and convert it to liquid fuels. $\mathbf{c} \mid \mathrm{A}$ broad range of lithoautotrophs can fix $\mathrm{CO}_{2}$ to produce fuels with reducing power from electrons or electrochemically generated electron shuttles, such as $\mathrm{H}_{2}$ and formic acid. $\mathbf{d}$ | Low-throughput methane from landfill or natural gas wells that is otherwise flared can be used directly by methanotrophs to produce fuels, or it can be converted to methanol $\left(\mathrm{CH}_{3} \mathrm{OH}\right)$ and can then be utilized by

Alkanes

Organic molecules with the general formula $\mathrm{C}_{n} \mathrm{H}_{2 n+2}$ 


\section{Cellulose}

A long-chain linear

polysaccharide of

$\beta(1-4)$-linked D-glucose; this polysaccharide is a major energy and carbon storage material in plants.

\section{Hemicellulose}

A group of heteropolymers in plant cell walls, commonly

consisting of mainly pentoses (such as xylose, arabinose and mannose) and some hexoses (such as glucose).

Lignin

A group of heterogeneous crosslinked polymers that are rich in phenolic moieties and provide structural support in plant cell walls.

Synthetic gas

(Syngas). A mixture of $\mathrm{CO}$ and $\mathrm{H}_{2}$

Fischer-Tropsch reaction A process that converts a mixture of $\mathrm{H}_{2}$ and $\mathrm{CO}$ to liquid fuels using cobalt, iron, or ruthenium as catalysts at $150-350^{\circ} \mathrm{C}$

Wood-Ljungdahl pathway $\mathrm{A} \mathrm{CO}_{2}$-fixing pathway that is found in certain bacterial and archaeal species and that synthesizes acetyl-CoA; also known as the reductive acetyl-CoA pathway.

Cellulosomes

Cell surface-attached multi-enzyme complexes that are produced by several cellulolytic bacteria for lignocellulose degradation volume) of bioprocesses are often too low to justify industrial applications. Coupled with the need for extremely high volumes and a low cost of biofuels, this means that a high yield and a high productivity are required for every step of biofuel generation. Many of these problems can be addressed by engineering microorganisms with redesigned metabolic systems to improve yield and productivity, such that the raw material requirement, manufacturing plant scale, capital intensity and operating cost are minimized. Notably, success in microbial engineering can also affect land use and biodiversity. For example, a 10\% increase in biofuel yield from lignocellulose translates to a $10 \%$ saving in land usage because less raw material is required. Similarly, a $10 \%$ increase in microalga productivity results in a $10 \%$ reduction in the footprint of microalga cultivation. Engineering microorganisms to utilize diverse raw materials efficiently can also preserve natural biodiversity by reducing the need for importing non-native plants.

This Review focuses specifically on problems that are relevant to microbiology, rather than on other aspects of biofuels. We first describe the status of, and challenges in, the utilization of different substrates, including lignocellulose, $\mathrm{CO}_{2}$ and methane, followed by a discussion of the major pathways that lead to the production of key fuel compounds. We focus on the design and optimization of microorganisms beyond their natural capabilities.

\section{Substrates for biofuel production}

To reduce or avoid collateral emissions, raw materials for sustainable biofuel production should eventually come from atmospheric $\mathrm{CO}_{2}$ by net increased global carbon fixation or from carbon that is otherwise released as GHGs without being efficiently utilized. These materials must be available in sufficient quantities to displace a meaningful portion of the fossil fuels that are currently used. We do not discuss how these raw materials are derived in a sustainable way, but focus on how they can be converted to biofuels.

Biomass utilization. Plant biomass is the most abundant renewable resource on Earth (BOX 1). Typical plant biomass contains approximately $40-50 \%$ cellulose, $20-40 \%$ hemicellulose and $20-35 \%$ lignin, bound together in a complex structure. Because of the encapsulation of cellulose by lignin and hemicellulose, the hydrophobicity of lignin and the crystallinity of cellulose, the complex plant material has to be deconstructed to simpler chemical forms before further processing. These intermediate forms include sugar $^{13}$, synthetic gas (syngas) $)^{14}$, organic acids ${ }^{15,16}$ and methane ${ }^{17}$. Utilization of lignocellulose through syngas can be accomplished using thermochemical processes ${ }^{14}$, followed by the Fischer-Tropsch reaction ${ }^{18}$ or microbial conversion ${ }^{19}$ through the $\mathrm{CO}_{2}$-fixing Wood-Ljungdahl pathway ${ }^{20}$. The conversion of lignocellulose to organic acids or methane is achieved using mixed anaerobic cultures similar to those used in rumen fermentation ${ }^{21}$. All of these processes have been explored for biofuel generation, but more research at the microbial, molecular and biochemical levels is needed to achieve their full potential as strategies to replace fossil fuels.
Currently, lignocellulose deconstruction to sugars generally starts with a pretreatment process followed by enzymatic hydrolysis. The pretreatment process can be physical, chemical, biological or a combination of these $\mathrm{e}^{22,23}$. The pretreated biomass is then hydrolysed by either non-complexed cellulase enzyme cocktails or by cellulolytic microorganisms ${ }^{13}$. Industrial production of non-complexed cellulase cocktails predominantly relies on the mesophilic wood soft rot fungus Trichoderma reesei (teleomorph Hypocrea jecorina), because of the high secreted protein yield of this species in comparison with other microorganisms $\mathrm{s}^{24,25}$. These cocktails typically contain at least three types of enzymes: cellobiohydrolases, endoglucanases and $\beta$-glucosidases (FIG. 2a). Cellobiohydrolases hydrolyse $\beta(1-4)$-D-glucosidic linkages in cellulose and cellodextrins, generating cellobiose from either the reducing (type I cellobiohydrolases) or the non-reducing (type II cellobiohydrolases) ends of the polymeric chains ${ }^{26,27}$. Endoglucanases cut internal bonds randomly in the amorphous regions within a cellulose polymer, freeing more cellulose ends for cellobiohydrolases to act on. Indeed, synergy between cellobiohydrolases and endoglucanases has been reported ${ }^{28}$. $\beta$-glucosidases then hydrolyse the disaccharide cellobiose to glucose. Notably, both type $\mathrm{I}^{29}$ and type $\mathrm{II}^{30}$ cellobiohydrolases and endoglucanases ${ }^{30}$ from $H$. jecorina have been engineered to increase their optimal operating temperature from $60^{\circ} \mathrm{C}$ to $70^{\circ} \mathrm{C}$ by directed evolution. These engineered enzymes performed better than their wild-type counterparts, which demonstrates the benefit of using higher temperatures in cellulose hydrolysis. Furthermore, as the enzyme cost could account for up to $48 \%$ of the minimum ethanol selling price ${ }^{31,32}$, cellulases from other organisms, such as fungi belonging to the genera Penicillium, Acremonium and Chrysosporium, have been characterized ${ }^{33}$, but the cost of their production needs to be lower than that of the $T$. reesei enzymes to be industrially attractive.

In contrast to the secreted fungal proteins, cellulases and hemicellulases from anaerobic bacteria (such as C. thermocellum, Clostridium cellulolyticum and Clostridium cellulovorans) self-assemble on the cell surface to form microscopically visible protuberances called cellulosomes ${ }^{34,35}$ (FIG. 2b). The cellulosomes in C. thermocellum are the best studied ${ }^{35,36}$. At the core of the $C$. thermocellum cellulosome is the scaffoldin protein $\mathrm{CipA}^{37}$. This scaffoldin has nine type I cohesin modules that bind strongly to the type I dockerin modules on various secreted $C$. thermocellum cellulases, thus acting as the key assembly site for cellulosome super structure. CipA also has type II dockerin modules, which bind to the type II cohesin module on the cell surface, effectively anchoring the cellulosome onto the cell. The various enzymes that constitute the $C$. thermocellum cellulosome include endoglucanases (CelA and CelB), exoglucanases (CelS and CbhA), xylanases (XynA and XynC), mannanase (ManA) and lichenase $(\mathrm{LicB})^{38}$. C. thermocellum cellulosomes break down cellulose into a mixture of cellodextrins with an average length of four sugar units ${ }^{39}$, and these are taken up by cells through an adenosinebinding cassette system, followed by phosphorolytic 
a
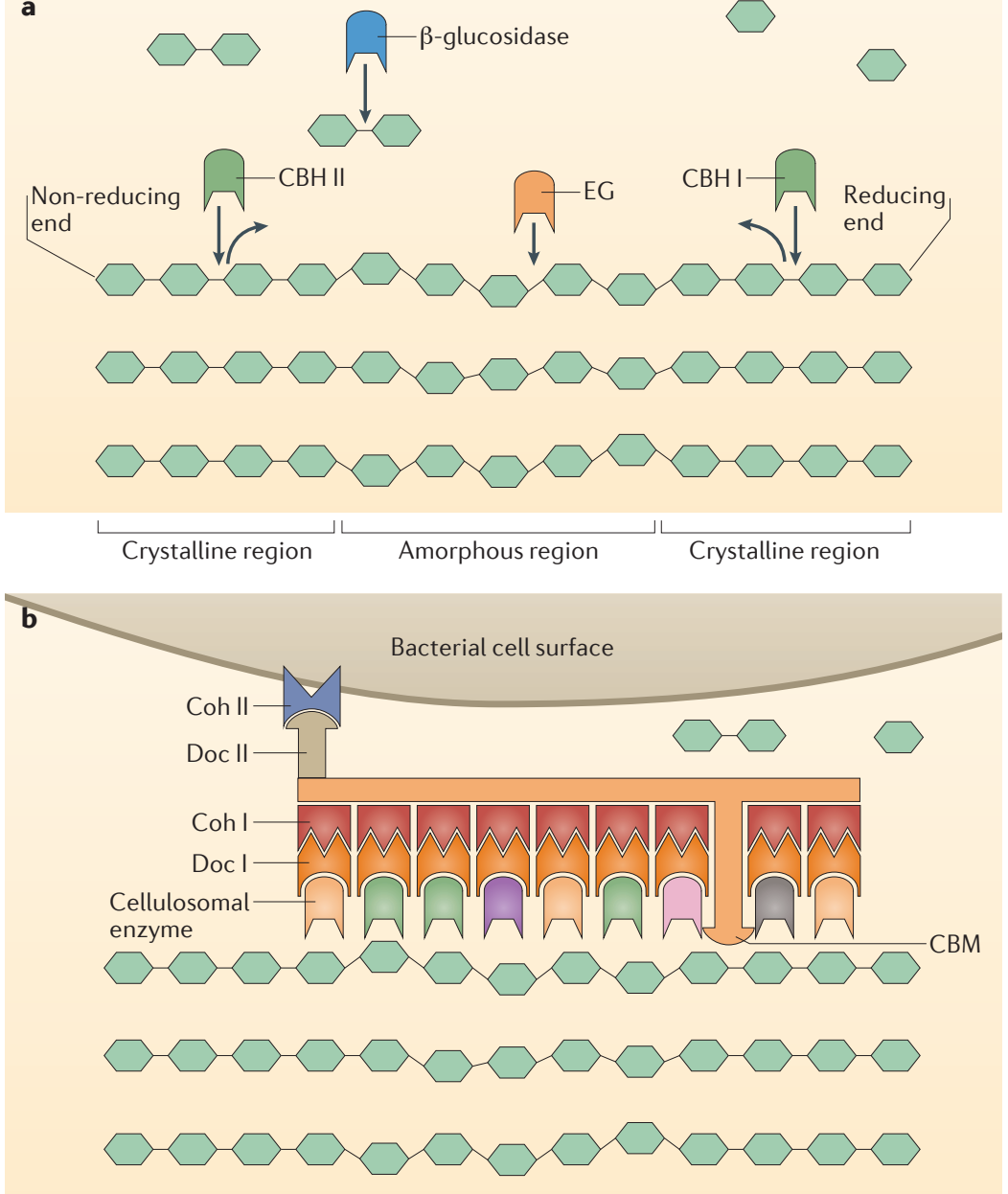

c

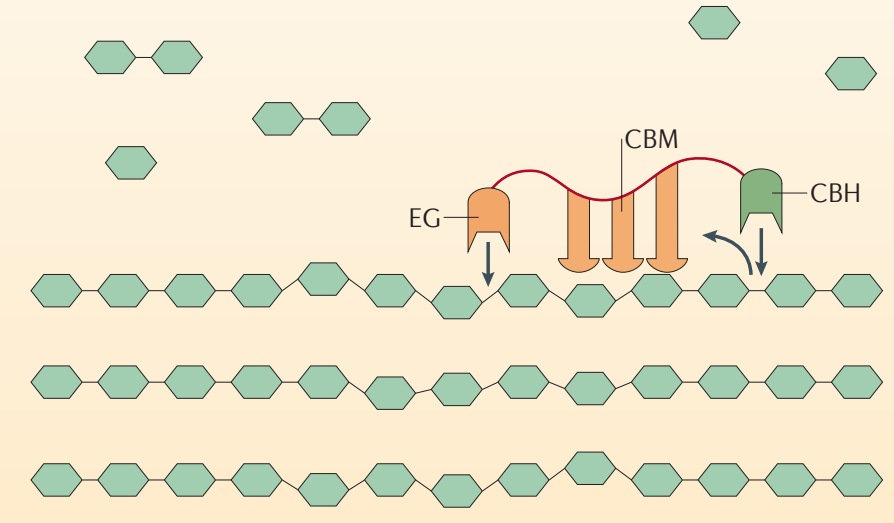

Figure 2 | Three modes of cellulose degradation in different organisms.

a | A simplified mechanism of action for fungal non-complexed cellulases. Cellobiohydrolases $(\mathrm{CBHs})$ are exoglucanases that cleave disaccharide units from the reducing or non-reducing end (type I or type II enzymes, respectively) of the cellulose molecule. $\beta$-glucosidase cleaves the disaccharides into glucose monomers. Endoglucanases (EGs) cleave bonds in the amorphous region of cellulose, generating ends that act as $\mathrm{CBH}$ substrates. $\mathbf{b}$ | The interaction of the Clostridium thermocellum cellulosome with cellulose polymers. Cohesin modules (Coh) in the cellulosomal scaffoldin (CipA) and on the bacterial cell surface bind to dockerin modules (Doc) in the scaffoldin and the cellulases, forming a large enzymatic complex that binds to cellulose through the scaffoldin carbohydrate-binding module (CBM). c | The mechanism of action for the bifunctional CelA protein of Caldicellulosiruptor bescii, which contains both $\mathrm{EG}$ and $\mathrm{CBH}$ modules as well as three CBMs. cleavage to save energy ${ }^{40}$. When used in combination, cellulosomes and non-complexed cellulases exhibit synergistic effects ${ }^{41}$ because they act through different mechanisms: non-complexed enzymes penetrate into cell walls and hydrolyse exposed microfibrils, whereas complexed enzymes have been reported to act by a peeling action ${ }^{42}$, exposing new reactive surfaces as solubilization proceeds.

The digestion mechanism of the anaerobic cellulolytic bacterium Caldicellulosiruptor bescii represents an interesting intermediate strategy between fungal non-complexed cellulases and clostridial cellulosomes (FIG. 2c). The most crucial and abundant enzyme for C. bescii cellulose degradation is $\mathrm{CelA}^{43}$. This enzyme has three carbohydrate-binding modules and two catalytic domains ${ }^{44}$, one with endoglucanase activity and the other with exoglucanase (cellobiohydrolase) activity. It has been demonstrated that the single enzyme CelA outperforms a mixture of fungal endoglucanase and exoglucanase $e^{44}$, which suggests that there is a benefit to having complementary catalytic units within the same enzyme molecule. However, the potential advantages of bacterial cellulose deconstruction remain to be realized industrially, and the current cellulosic biofuel plants all use fungal cellulases.

In addition to cellulose, lignocellulose also includes hemicellulose and lignin. Unlike the ordered structure of cellulose, the structures of hemicellulose are much more variable. Despite this structural diversity, the key catalytic modules of hemicellulases are either glycoside hydrolases, used for breaking glycosidic bonds, or carbohydrate esterases, used for side group hydrolysis ${ }^{45}$. A portion of hemicellulose can be hydrolysed using pretreatment methods ${ }^{22}$, such as dilute acid pretreatment. Furthermore, most organisms that are capable of cellulose degradation also express hemicellulases (such as xylanases, xylosidases, arabinofuranosidases, mannanases, and so on). Among the cellulolytic organisms, C. thermocellum represents an interesting case: this species has several hemicellulases in its enzyme repertoire, but the organism itself is unable to metabolize the pentoses released from hemicellulose hydrolysis ${ }^{46}$. Similarly, the main industrial ethanol producers, Saccharomyces cerevisiae and Zymomonas mobilis ${ }^{47}$, cannot utilize xylose, the major pentose in plant biomass, as a carbon source for biofuel production. In an attempt to circumvent this problem, S. cerevisiae ${ }^{48}$ and Zymomonas spp. ${ }^{49}$ have been engineered to utilize xylose, with varying degrees of success. However, simultaneous, efficient and complete utilization of hexose (which results from cellulose degradation) and pentose (which results from hemicellulose degradation) remain a challenge because all known D-xylose transporters are competitively inhibited by D-glucose ${ }^{50}$. Mutants that are insensitive to the inhibition ${ }^{50}$ have been isolated and may help solve this problem.

The third main component of lignocellulose, lignin, constitutes $20-35 \%$ of plant biomass. Lignin can be combusted to generate heat and electricity or gasified to syngas for further use. Converting lignin to fue ${ }^{51}$ or value-added products is challenging because of its structural diversity and product heterogeneity, which increase the cost of both conversion and product purification. Several chemical 
approaches exist for lignin conversion ${ }^{52}$. Biological transformation depends on ligninolytic enzymes, including laccases and peroxidases ${ }^{53}$, which are oxidative enzymes that are native to a large diversity of fungal hosts. Furthermore, several species of bacteria, such as Pseudonocardia autotrophica and Comamonas testosteroni, have been identified as producers of ligninolytic enzymes ${ }^{54}$. In bacteria, the products of aromatic catabolic pathways typically form compounds, such as catechol or protocatechuate, as central intermediates ${ }^{55}$. Therefore, improved utilization of lignin as a substrate in these pathways will probably stem from the ability to channel these catabolic intermediates into the specific metabolic pathways that are used for the production of chemicals ${ }^{56}$. As the lignin conversion process is likely to be complex and challenging, the products that are generated by this process need to justify the cost to make economic sense.

Direct $\mathrm{CO}_{2}$ utilization. An alternative to using biomass for biofuel production is to explore the ability of microorganisms to carry out the direct conversion of $\mathrm{CO}_{2}$ into energy-dense liquid fuels. Phototrophic organisms, such as eukaryotic microalgae and prokaryotic cyanobacteria, can fix $\mathrm{CO}_{2}$ with reducing power harnessed from sunlight, and these organisms can be metabolically engineered to produce fuel compounds directly (FIG. 1b).

The capacity of many microalgal species to produce large amounts of lipids (up to 70\% lipid per dry weight $)^{57}$ as storage products makes microalgal biomass an attractive resource for the production of biodiesel. Bioprospecting for algal strains with high lipid accumulation as well as superior growth and harvesting characteristics can provide suitable candidates ${ }^{58}$. Furthermore, modern approaches, such as nextgeneration sequencing ${ }^{59}$ and $\mathrm{RNAi}^{60}$, have provided insights into algal physiology and metabolism ${ }^{61}$ that can be explored for the production of biofuels. For example, RNA-sequencing technologies have helped to identify genes that are involved in the accumulation of triacylglycerol under conditions of nitrogen deprivation ${ }^{58}$, thus providing potential targets for the engineering of strains with a high level of lipid production. Geneediting techniques have also enabled the engineering of cyanobacteria, which are genetically more tractable than eukaryotic microalgae and therefore more versatile for the direct production of fuels and chemicals. For example, introducing exogenous biosynthetic pathways into Synechococcus elongatus PCC 7942 or Synechocystis sp. PCC 6803 has led to the production of various compounds directly from $\mathrm{CO}_{2}$ (REF. 62).

One major challenge for producing photosynthesisderived biofuels is to provide large light-exposing surfaces $^{63}$. Although open-pond cultivation systems are inexpensive, they need large areas of land and have problems with water loss, contamination and controlling the culture conditions ${ }^{64,65}$. By contrast, closed photobioreactors are costly for biofuel production ${ }^{64}$. In addition, the photosynthetic apparatus can use radiation within only a limited spectrum and intensity range, thus limiting photosynthetic microorganisms to only $\sim 50 \%$ of the incident solar energy. Furthermore, the photosynthetic apparatus is photo-inhibited above a certain light intensity ${ }^{66}$, and high temperatures and salt concentrations also present problems. Synechococcus sp. PCC 7002 displays favourable properties in tolerating heat and salts ${ }^{67}$. In general, biofuels that are derived directly from photosynthesis still need to compensate for many of the unique problems originating from light capturing and distribution to be economically viable.

Another option is to use electricity and lithoautotrophs to convert $\mathrm{CO}_{2}$ into liquid 'electrofuels' (REF. 68) (FIG. 1c). Owing to the higher efficiency of photovoltaic technologies compared with biological photosynthesis ${ }^{69}$, electrofuels could have better sun-to-fuel efficiency than photosynthesis-derived biofuels, in theory. Furthermore, the separation of light and dark reactions circumvents the expensive cultivation systems that are required for photosynthetic microorganisms. Moreover, as solar or windgenerated electricity is intermittent, the conversion of such electricity to liquid biofuel is the most energy-dense approach for long-term energy storage ${ }^{70}$ (BOX 1).

A broad range of lithoautotrophic microorganisms are capable of fixing $\mathrm{CO}_{2}$ with reducing power from electron shuttles, such as $\mathrm{H}_{2}$ and formic acid. $\mathrm{H}_{2}$ can be produced on cathodes from water splitting, whereas formic acid can be synthesized electrochemically using water and $\mathrm{CO}_{2}$. Lithoautotrophic organisms, such as Cupriavidus necator (formerly known as Ralstonia eutropha), have been engineered to produce biofuels from $\mathrm{CO}_{2}$ using $\mathrm{H}_{2}$ (REF. 71, 72) or formic acid ${ }^{71-73}$. Similarly, the $\mathrm{H}_{2}$-utilizing heterotroph Pyrococcus furiosus has been engineered ${ }^{74}$ to incorporate $\mathrm{CO}_{2}$ using a portion of the 3-hydroxypropionate/4-hydroxybutyrate $\mathrm{CO}_{2}$ fixation pathway from Metallosphaera sedula to produce 3-hydroxypropionic acid. However, the low solubility of $\mathrm{H}_{2}$ and low mass transfer rate in these processes may increase the cost of biofuel production.

Alternatively, some autotrophic microorganisms, such as Geobacter spp., can directly accept electrons from cathodes for anaerobic respiration ${ }^{75}$. Recently, a wide range of acetogenic microorganisms, including Sporomusa spp., Clostridium spp. and Moorella thermoacetica, have been shown to be capable of accepting electrons from a cathode and fixing $\mathrm{CO}_{2}$ into acetate and a small amount of 2-oxobutyrate ${ }^{76,77}$, indicating their potential to produce biofuel from $\mathrm{CO}_{2}$ with direct electron feeding. However, bioreactors with large electrode surfaces are required to establish this process, and this will inevitably increase the cost associated with producing biofuels using this strategy.

Methane utilization. Methane can be produced from landfill or by anaerobic digestion of various organic wastes and is also the major component in natural gas, the production of which has undergone a dramatic surge in the past decade. Unfortunately, a substantial number of natural gas wells do not generate a high enough output for use, and the gas product is flared to $\mathrm{CO}_{2}$ or leaked out. As methane is a more potent GHG than $\mathrm{CO}_{2}$ (REF. 12), there is increasing pressure to find ways of more efficiently using methane as a carbon source. Microbial methane oxidation acts as the only known biological sink of methane, as methanotrophs limit the release of methane from many methanogenic areas ${ }^{78}$. 
The conversion of methane into liquid biofuels, such as ethanol or 1-butanol, is thermodynamically favourable and can be accomplished through chemical or biological methods. Chemical methods, such as the Fischer-Tropsch process, have high capital costs, as they are energy intensive processes that utilize high temperatures and pressures ${ }^{79}$. By contrast, biological methods (FIG. 1d) first require the oxidation of methane to methanol under physiological conditions. In all methaneassimilating microorganisms, this oxidation step is carried out using methane monooxygenase (MMO). MMO exists in two forms: soluble MMO (sMMO) and membrane-bound particulate MMO (pMMO). Most methanotrophs accommodate pMMO by producing internal cytoplasmic membrane stacks ${ }^{80}$. sMMO is a unique member of a family of bacterial monooxygenases that are able to oxidize methane, and the reaction mechanism of this enzyme has recently been elucidated ${ }^{81}$.

The application of methanotrophs as platforms for biofuel production requires three main obstacles to be overcome: the efficiency of methane activation must be improved, alternative pathways for the production of liquid fuels must be found and productivity within large-scale bioreactors must be increased ${ }^{79}$. For example, MMO oxidizes methane to methanol in the first step of methane assimilation, but requires a high-energy electron donor, such as NADPH, as an energy input to functionalize the otherwise inert methane molecule. Although this step is thermodynamically favourable and highly exothermic, no energy output is generated, resulting in the loss of approximately $40 \%$ of the energy within the methane molecule ${ }^{79}$. This large energy loss can, in principle, be addressed by the direct engineering of enzymes for alternative mechanisms of oxidizing methanol ${ }^{79}$. These envisioned methane-activation strategies may use a dioxygenase-like enzyme that is capable of oxidizing two methane molecules simultaneously. However, such an enzyme has not been found or engineered successfully to date.

The oxidized product of methane, methanol, is used by methanotrophs and methylotrophs through the ribulose monophosphate (RuMP) pathway, the serine cycle or the assimilation of $\mathrm{CO}_{2}$ through the Calvin cycle after its complete oxidation ( $\mathrm{BOX} 2$ ). The recently demonstrated methanol condensation cycle ${ }^{82}$ illustrates how pathways can be optimized for biofuel production from methanol.

Finally, finding appropriate conditions for cultivating methanotrophs is another challenge that has yet to be met. One intrinsic problem is the low solubility of methane, as well as poor kinetics of the enzymes that metabolize methane ${ }^{83}$. These problems need to be solved to make biofuel production from methane viable in an industrial setting.

\section{Biofuel production pathways}

Following the saccharification of biomass or the assimilation of carbon from $\mathrm{CO}_{2}$ or methane, these raw materials are metabolized to either pyruvate or acetyl-CoA. These are common starting metabolites from which the biofuel ethanol can be directly produced. Several pathways can increase the carbon chain length and convert the metabolites to other fuel compounds, including the keto acid pathway, CoA-dependent reverse $\beta$-oxidation, fatty acid biosynthesis and the isoprenoid pathway (FIG. 3). Some longer-chain alcohols, esters and alkanes have higher energy densities and are more compatible with the existing infrastructure than ethanol. Very roughly, $\mathrm{C}_{8}$ compounds are suitable for substituting gasoline, $\mathrm{C}_{12}$ compounds for aviation fuel and $\mathrm{C}_{16}$ compounds for diesel, but other fuel properties need to be considered.

Although parts of these metabolic pathways may exist in some microorganisms, few have a complete pathway or can synthesize the desired compound efficiently. In principle, any pathway can be engineered into any host to produce the desired fuel, but the challenge is to increase the titre, yield and productivity associated with biofuel production.

Ethanol pathways. In microorganisms, ethanol can be produced from pyruvate decarboxylation with or without going through acetyl-CoA. For example, S. cerevisiae and Z. mobilis, the two most productive ethanol producers, directly decarboxylate pyruvate, followed by reduction to ethanol, without using acetyl-CoA. By contrast, most other microorganisms, including Escherichia coli and Clostridium spp., use CoA to activate the acyl group during pyruvate decarboxylation, before reduction to ethanol. This difference implies that direct decarboxylation is a more efficient route, and this direct pathway has been engineered into many other organisms.

Importantly, the production strain must be robust against several challenges in industrial settings, such as high ethanol concentration ${ }^{84}$, high temperature ${ }^{85}$ and high acid levels ${ }^{86}$, and must be resistant to contamination in minimally sterilized conditions. Compared with S. cerevisiae, Z. mobilis is more tolerant to ethanol ${ }^{87}$. In addition, $Z$. mobilis can fix nitrogen ${ }^{88}$, achieving higher specific ethanol production rates and lower cell mass yields when $\mathrm{N}_{2}$ is used as the nitrogen source rather than ammonium $^{88}$. However, S. cerevisiae is more tolerant to acid, insensitive to phage infection and more robust against contamination; indeed, most industrial producers use $S$. cerevisiae because of its robustness under industrial conditions.

Another strategy to produce biofuel, termed consolidated bioprocessing ${ }^{89}$, is to achieve cellulose hydrolysis and fuel production in one reactor without enzyme supplementation, using one or several organisms (FIG. 1a). The cellulolytic thermophile C. thermocellum is one of the leading candidates for consolidated bioprocessing owing to its rapid cellulolytic function and growth rate. C. thermocellum has a non-conventional glycolytic pathway ${ }^{90}$ with no identified pyruvate kinase. Instead, pyruvate is produced through a malate shunt, and C. thermocellum conserves energy using electron-bifurcating enzymes ${ }^{91,92}$. A less characterized cellulolytic thermophile, C. bescii, has also emerged as a potential candidate for consolidated bioprocessing ${ }^{93}$, owing to its impressive rate of biomass deconstruction. This organism is not naturally ethanogenic, but has been engineered to produce ethanol (yielding $700 \mathrm{mg}$ ethanol $\mathrm{l}^{-1}$ ); this was achieved by knocking out the competing lactate dehydrogenase and 
expressing a bifunctional acetylaldehyde-alcohol dehydrogenase from C. thermocellum ${ }^{94}$. Similarly, T. reesei has also been engineered to produce ethanol (yielding about $10 \mathrm{~g}_{\text {ethanol }} \mathrm{l}^{-1}$ ), through several rounds of genome shuffling and strain selection ${ }^{95}$. Finally, instead of engineering native cellulolytic organisms to produce ethanol, another approach is to engineer an ethanol producer to digest cellulose. Examples include engineering $S$. cerevisiae, E. coli or Z. mobilis to digest cellulose through the expression of heterologous cellulolytic enzymes ${ }^{96,97}$. However, much work is still required to bring biofuel production by these engineered microorganisms to an industrial level.

\section{Box 2 | Biological methane and methanol conversion}

In aerobic methane-assimilating microorganisms, methane oxidation is carried out using methane monooxygenase (MMO) (see the figure). The product, methanol $\left(\mathrm{CH}_{3} \mathrm{OH}\right)$, is further oxidized to formaldehyde $\left(\mathrm{CH}_{2} \mathrm{O}\right)$ using pyrroloquinoline quinone (PQQ)-dependent ${ }^{168}$ or NAD-dependent ${ }^{169}$ methanol dehydrogenase (Medh), or methanol oxidase (Mox ${ }^{170}$. Methanotrophs are able to assimilate formaldehyde by $\mathrm{C}_{1}$ assimilation pathways, including the serine cycle ${ }^{171}$, the ribulose monophosphate (RuMP) pathway ${ }^{172}$ and the recently engineered methanol condensation cycle (MCC) ${ }^{82}$ (see the figure). Alternatively, formaldehyde can be oxidized completely to $\mathrm{CO}_{2}$ then assimilated through the Calvin cycle ${ }^{173}$.

The serine cycle ${ }^{171}$ assimilates formaldehyde using 5,10-methylene tetrahydrofolate (5,10-MTHF) as an intermediate to condense with glycine and generate serine using a serine hydroxymethyltransferase (SHMT), GlyA. Conversion of serine to phosphoenolpyruvate (PEP) and the subsequent carboxylation of PEP generates the $\mathrm{C}_{4}$ compound oxaloacetate (OAA). OAA can then be converted into malyl-CoA and split to ultimately yield glycine, which is used to regenerate the cycle, and acetyl-CoA, which is used for cell growth ${ }^{171}$. This cycle requires both ATP and $\mathrm{NADH}$, which must come from additional oxidation of reduced carbon to $\mathrm{CO}_{2}$.

In the RuMP pathway ${ }^{172}$, formaldehyde is condensed with ribulose5-phosphate (Ru5P) to generate fructose-6-phosphate (F6P) using hexulose-6-phosphate $(\mathrm{H} 6 \mathrm{P})$ as an intermediate. This F6P is then converted into the glycolytic intermediate, dihydroxyacetone phosphate (DHAP), which is then converted to acetyl-CoA through the Embden-Meyerhof-Parnas (EMP) pathway or Entner-Doudoroff (ED) pathway. This cycle is useful for growth, but it requires ATP and loses one carbon in the decarboxylation of pyruvate to acetyl-CoA.

The recently engineered $\mathrm{MCC}^{82}$ addresses the issue of carbon loss by using the key enzyme X5P phosphoketolase (Xpk), which splits xylulose5-phosphate (X5P) into acetyl-phosphate and glyceraldehyde-3phosphate (G3P). MCC functions as a combination of the RuMP cycle and non-oxidative glycolysis (NOG) ${ }^{159}$ (see BOX 3), but avoids the use of ATP ${ }^{82}$. Similarly to the RuMP cycle, it also uses Ru5P to assimilate formaldehyde, but the G3P generated by Xpk is carbon rearranged to regenerate Ru5P. The intermediate acetyl-phosphate (AcP) can be converted to acetyl-CoA and then to ethanol or 1-butanol. The stoichiometric amount of NADH gained from methanol oxidation by Medh balances the reducing power required to reduce acetyl-CoA to ethanol or butanol. The net reaction is the condensation of two methanol molecules to one ethanol molecule, or four methanol molecules to one 1-butanol molecule, independently of ATP or reducing power. This pathway avoids the decarboxylation of pyruvate and achieves complete carbon conservation in converting methanol to ethanol or 1-butanol with the loss of only water. Complete carbon conservation from feedstock to biofuel is important both because it decreases the raw material cost and reduces the emission of greenhouse gas.

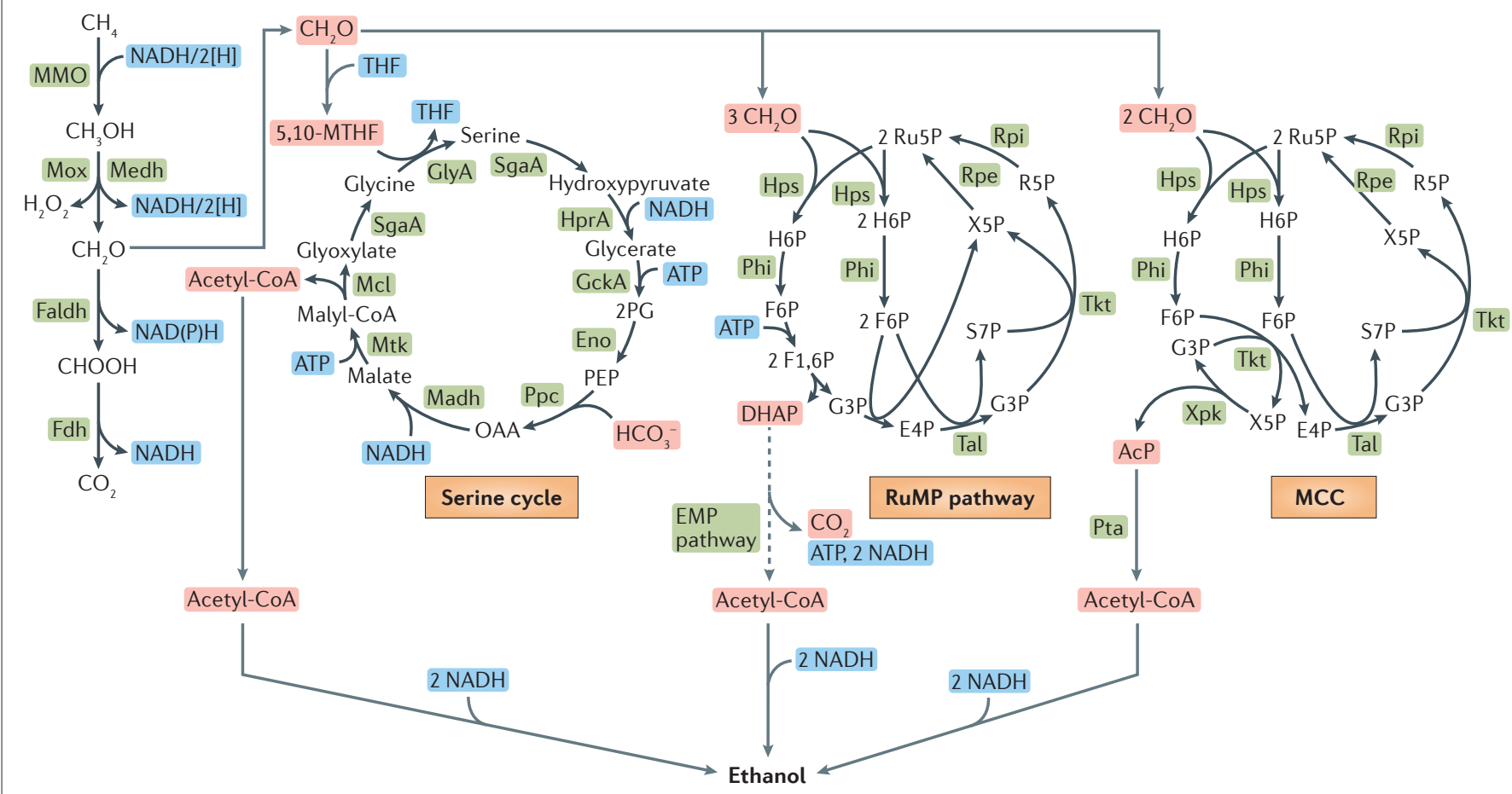

E4P, erythrose-4-phosphate; Eno, enolase; F1,6P, fructose-1,6-bisphosphate; Faldh, formaldehyde dehydrogenase; Fdh, formate dehydrogenase;

GckA, glycerate-2-phosphate kinase; HprA, hydroxypyruvate reductase; Hps, H6P synthase; Madh, malate dehydrogenase; Mcl, malyl-CoA lyase; Mtk, malate thiokinase; PG, phosphoglycerate; Phi, phosphohexulose isomerase; Ppc, PEP carboxylase; Pta, phosphate acetyltransferase; R5P, ribose-5-phosphate; Rpe, R5P epimerase; Rpi, R5Pisomerase; S7P, sedoheptulose-7-phosphate; SgaA, serine-glyoxylate aminotransferase; Tal, transaldolase; Tkt, transketolase. 


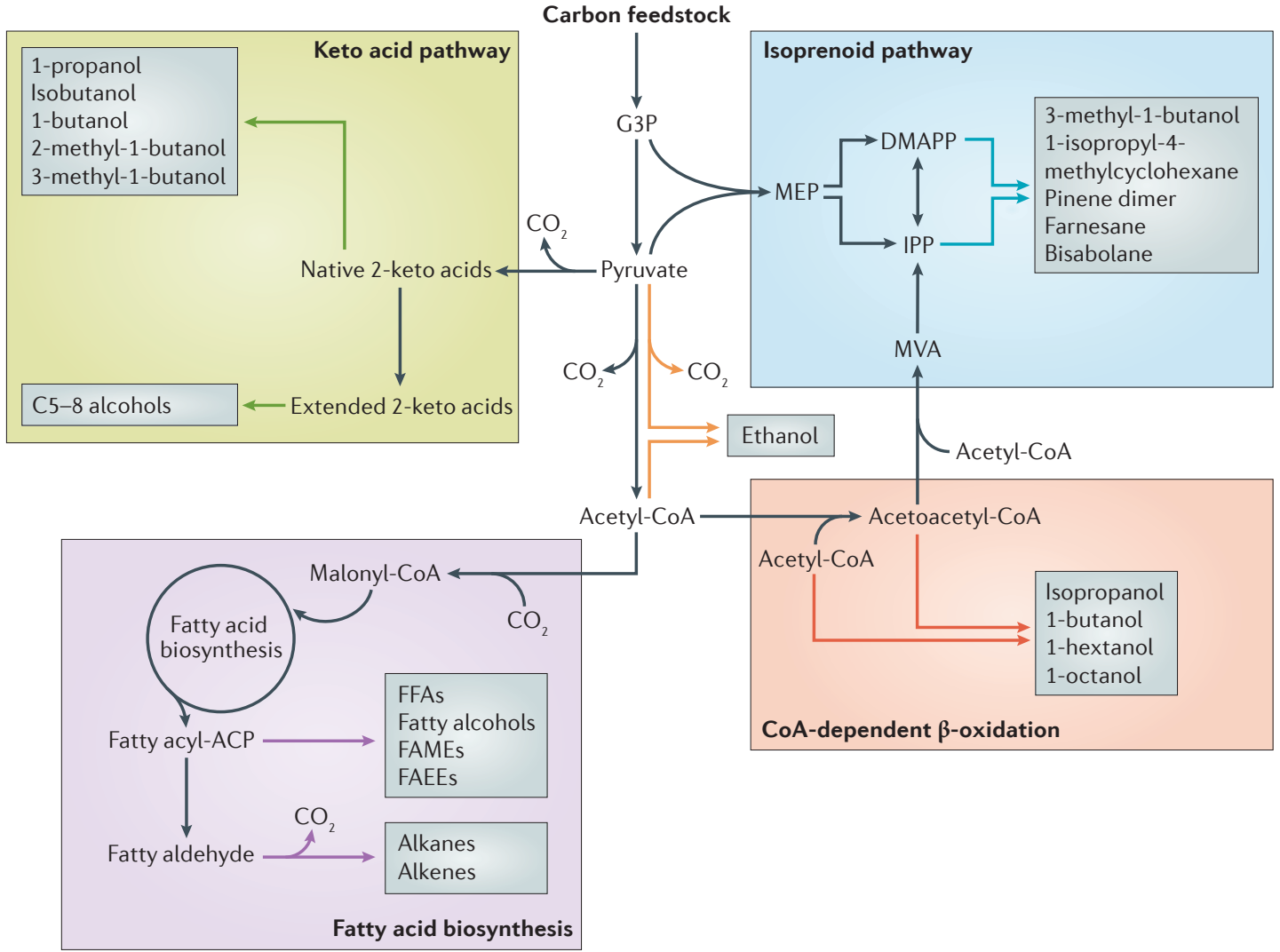

Figure 3 | Biosynthetic pathways of biofuels. Ethanol is produced from either pyruvate or acetyl-CoA (orange arrows), with acetaldehyde as a common intermediate. The keto acid pathway (green arrows) can be used to produce both branched and straight-chain alcohols. It uses parts of amino acid biosynthesis pathways for keto acid chain elongation. This is followed by decarboxylation and reduction of the keto acid, analogous to the conversion of pyruvate to ethanol. Fatty acid synthesis (purple arrows) extends acyl-acyl carrier proteins (ACPs) in a cyclical manner, using malonyl-CoA as a precursor. Fatty acyl-ACPs may be converted into free fatty acids (FFAs) with acyl-ACP thioesterase. FFAs can be esterified to esters, such as fatty acid methyl esters (FAMEs) or fatty acid ethyl esters (FAEEs), reduced to fatty alcohols, or reduced to fatty aldehydes followed by decarbonylation to alkanes and alkenes. The CoA-dependent pathway (red arrows) uses reverse $\beta$-oxidation chemistry for the production of higher alcohols or decarboxylation of the precursor acetoacetyl-CoA for the production of isopropanol. Isopentenyl pyrophosphate (IPP) and dimethylallyl pyrophosphate (DMAPP), the universal precursors of isoprenoid biofuel biosynthesis (blue arrows), may be produced either through the mevalonate (MVA) or methylerythritol-4-phosphate (MEP) pathway. G3P, glyceraldehyde-3-phosphate.

Keto acid pathways. Analogous to the decarboxylation of pyruvate (a keto acid) for ethanol production in S. cerevisiae and Z. mobilis, any longer-chain keto acid can be decarboxylated and reduced to longer-chain alcohols $^{98,99}$ (FIG. 3). This strategy involves chain elongation at the level of 2-keto acids, which are used in branched chain amino acid biosynthesis. Keto acid chain elongation starts through acetohydroxyacid synthase in the valine biosynthesis pathway, or isopropylmalate synthase in the leucine biosynthesis pathway, followed by isomerization, reduction (or oxidation) and dehydration to regenerate the 2-keto acid functional group. For example, alcohols, such as isobutanol, 1-butanol, 2-methyl-1butanol, 3-methyl-1-butanol and 2-phenylethanol, can be produced in E. coli after expressing keto acid elongation enzymes and keto acid decarboxylation enzymes ${ }^{98}$. In particular, an E. coli strain $(\Delta a d h, \Delta l d h, \Delta f r d, \Delta f n r$, $\Delta p t a, \Delta p f l B$ ) was engineered to produce isobutanol at a high titre (22 g isobutanol $\mathrm{l}^{-1}$, which represents $86 \%$ of the theoretical yield $)^{98}$ by overexpressing several enzymes: 2-hydroxy-3-ketol-acid reductoisomerase (encoded by $i l v C$ ), dihydroxy-acid dehydratase (encoded by $i l v D$ ) and alcohol dehydrogenase (encoded by $y q h D$ ), which are native to E. coli, and two heterologous enzymes, catabolic acetolactate synthase (encoded by alsS from Bacillus subtilis) and ketoisovalerate decarboxylase (encoded by kivD from Lactococcus lactis). Isobutanol is currently being commercialized as a biofuel using this pathway.

Additional efforts can further increase the yield of isobutanol production under anaerobic conditions, including the engineering of ketol-acid reductoisomerase and alcohol dehydrogenase ${ }^{100}$. Isobutanol has also been produced from sugar in other engineered organisms, such as yeast (yielding $0.23 \mathrm{~g}^{-1}$ ) 101 and B. subtilis (yielding $\left.2.62 \mathrm{~g}^{-1}\right)^{102}$, from cellulose using $C$. thermocellum (yielding $\left.5.4 \mathrm{~g}^{-1}\right)^{103}$ and from cellobiose using E. coli (yielding $\left.8 \mathrm{~g} \mathrm{l}^{-1}\right)^{104}$. The advantage of these keto acid pathways is their compatibility with many organisms, as they build on the amino acid biosynthesis pathways already present and can be expanded in several ways ${ }^{105}$. However, because 
Acyl carrier protein A protein molecule that transfers the acyl group during fatty acid biosynthesis. these pathways have been developed only recently, there are less established markets for the commercialization of their products.

CoA-dependent reverse $\beta$-oxidation. CoA-dependent reverse $\beta$-oxidation is a pathway that uses the same chemistry as $\beta$-oxidation for fatty acid degradation, but in the reverse direction. In contrast to fatty acid biosynthesis, this pathway uses CoA as opposed to acyl carrier protein (ACP) to activate the acyl group. The pathway is used to produce primary alcohols, such as 1-butanol and 1-hexanol, or the secondary alcohol isopropanol in many Clostridium spp. In this pathway, two acetyl-CoA molecules are condensed to produce acetoacetyl-CoA, which then reverse $\beta$-oxidizes ${ }^{106,107}$ to produce 1-butyrylCoA. This acyl-CoA can then be reduced to produce 1 -butanol ${ }^{106}$, or go through the cycle again to increase the chain length by two carbon atoms in each cycle before reduction to 1-hexanol, 1-octanol or even longerchain alcohols ${ }^{107}$. Acetoacetyl-CoA can be converted to isopropanol after decarboxylation ${ }^{108}$.

CoA-dependent reverse $\beta$-oxidation has also been engineered into several organisms that do not possess this pathway, such as E. coli (yielding $\left.15 \mathrm{~g}_{\text {butanol }} \mathrm{l}^{-1}\right)^{106}$, S. cerevisiae (yielding $0.0025 \mathrm{~g}^{2}$ butanol $\left.\mathrm{1}^{-1}\right)^{109}$, B. subtilis (yielding $\left.0.024 \mathrm{~g}_{\text {butanol }} \mathrm{l}^{-1}\right)^{110}$, Pseudomonas putida (yielding $0.05 \mathrm{~g}$ butanol $\left.\mathrm{l}^{-1}\right)^{110}$ and $S$. elongatus (yielding $\left.0.3 \mathrm{~g}_{\text {butanol }}{ }^{-1}\right)^{111}$.

Notably, CoA-dependent reverse $\beta$-oxidation also enables the production of odd-chain alcohols, as acetylCoA can be condensed with propionyl-CoA if a source of propionate is available ${ }^{112}$. Propionyl-CoA can be synthesized through ketobutyrate ${ }^{113,114}$, which is a metabolite downstream of the threonine biosynthesis pathway, or through the 1,2-propandiol pathway ${ }^{115}$. However, the production of odd-chain alcohols loses redox potential, which results in lower yields, unless properly balanced by pairing a redox-deficient pathway with a redox-surplus pathway ${ }^{114}$, whereas the production of even-chain alcohols from carbohydrates is redox balanced. Therefore, in general, the production of even-chain alcohols from carbohydrates is more efficient than the production of odd-chain alcohols because it does not waste redox equivalents.

The production of acetone, 1-butanol and ethanol (ABE fermentation) by Clostridium acetobutylicum ${ }^{116,117}$ was one of the largest industrial fermentation processes in the early twentieth century. However, when the 1-butanol pathway was introduced into E. coli, the butyryl-CoA dehydrogenase-electron-transferring flavoprotein (Bcd-Etf) complex (a bifurcating enzyme ${ }^{91}$ involving both ferredoxin and $\mathrm{NADH}$ as electron mediators) was poorly expressed. To overcome this problem, an NADH-dependent enzyme, trans-enyol-CoA reductase (Ter), was used ${ }^{106,118}$. Further engineering to achieve accumulation of the precursor acetyl-CoA and the cofactor NADH provided more driving force ${ }^{106}$ and achieved a high-titre production of 1-butanol (15 g l-1, or $30 \mathrm{~g} \mathrm{l}^{-1}$ with in situ product removal $)^{106}$. Similarly, engineering $E$. coli to express $t h l$ (which encodes an acetylCoA acetyltransferase from C. acetobutylicum), ato $A D$ (which encodes an acetoacetyl-CoA transferase from E. coli), adc (which encodes an acetoacetate decarboxylase from C. acetobutylicum) and adh (which encodes a secondary-alcohol dehydrogenase from Clostridium beijerinckii) resulted in the production of isopropanol $\left(143 \mathrm{~g} \mathrm{l}^{-1}\right)^{108}$ in a gas-stripping bioreactor. Furthermore, the $\mathrm{ABE}$ fermentation products were also upgraded by chemical catalysis ${ }^{117}$ to longer-chain alkanes that can be used for gasoline, jet fuel and diesel.

Finally, the CoA-dependent pathway can also be used to produce acids by hydrolysis of the CoA-acylated intermediates, generating butyric acid ${ }^{119}$ and hexanoic $\operatorname{acid}^{120}$. These acids can be transformed to fuel compounds by hydrogenation if the cost can be justified. The CoA-acylated compounds in this pathway may also be condensed with alcohols produced from various pathways to form esters, through the expression of alcohol $O$-acyltransferase ${ }^{105}$.

Fatty acid biosynthesis. Fatty acid biosynthesis uses similar chemistry to $\beta$-oxidation for fatty acid degradation, but uses ACP for acyl group activation. In mammals and yeast, cytosolic fatty acid synthesis is mediated through one or two multidomain, multifunctional proteins, termed type I fatty acid synthases (FASs). By contrast, in most bacteria and in the mitochondria and chloroplasts of eukaryotic cells, fatty acid synthesis is catalysed by dissociated, individual gene products, termed type II FASs. Fatty acid synthesis is typically initiated by malonyl-CoA, which is transacylated to malonyl-ACP. The fatty acid chains are extended in a cyclical manner using ACPactivated intermediates. In mammals, free fatty acids (FFAs) are formed from fatty acyl-ACPs using fatty acylACP thioesterases. In yeast, the final acyl-ACP product (usually C16:0) of cytosolic FAS is transferred to CoA by an intrinsic transferase reaction centre and released as palmitoyl-CoA ${ }^{121}$. In bacteria, acyl-ACP is directly transferred to lipids by an acyl-transferase.

The use of acyl compounds as biofuels requires that they be esterified to esters, decarboxylated to alkanes or alkenes, or reduced to fatty alcohols ${ }^{122}$ (FIG. 3). The synthesis and degradation of fatty acids are tightly regulated ${ }^{123-125}$ and represent key targets for metabolic engineering. For example, E. coli fatty acid biosynthesis is subject to feedback inhibition by acyl-ACP, but this inhibition can be released by the overexpression of thioesterase ${ }^{126}$, which results in the production of FFAs. These FFAs can then be converted to acyl-CoA by acyl-CoA ligase. AcylCoA can be converted to fatty alcohols by fatty acyl-CoA reductases, or to fatty acid ethyl esters (FAEEs) by ester synthase, using endogenously synthesized ethanol ${ }^{122}$.

FAEEs are a desirable product because they can act as potential diesel substitutes. Furthermore, the chain length of FAEEs can be controlled by expressing different thioesterases with different substrate specificities ${ }^{122}$. E. coli has been engineered to produce FAEE (yielding $680 \mathrm{mg} \mathrm{l}^{-1}$, which represents $9.4 \%$ of the theoretical yield) with an organic phase overlay to prevent evaporation ${ }^{122}$. Fatty acyl-ACP or FFAs can be further converted to alkenes and alkanes. For example, an E. coli strain was engineered to produce alkanes and alkenes with length 
$\mathrm{C}_{13-17}$ (yielding approximately $80 \mathrm{mg} \mathrm{l}^{-1}$ ) 127 from acyl-ACP. This strain uses heterologous expression of a cyanobacteria acyl-ACP reductase, which reduces a saturated or unsaturated fatty acyl-ACP to the corresponding aldehyde, and an aldehyde decarbonylase, which splits the aldehyde to alkane (or alkene) and $\mathrm{CO}^{127}$. Alternatively, alkanes have been produced from FFAs in E. coli (yielding $6 \mathrm{mg} \mathrm{l}^{-1}$ ) using the fatty acid reductase (FAR) complex, encoded by the genes $\operatorname{lu} x C$, $\operatorname{lu} x D$ and $\operatorname{lu} x E$ from the bioluminescent bacterium Photorhabdus luminescens, followed by decarbonylation of the resultant fatty aldehydes using aldehyde decarbonylase (NpAD) cloned from Nostoc punctiforme ${ }^{128}$.

Appropriate gasoline substitutes include mediumchain hydrocarbons $\left(\mathrm{C}_{4-12}\right)$, but microbial fatty acid production typically generates longer $\left(\mathrm{C}_{14-18}\right)$ fatty acids. Two strategies have been reported for reducing hydrocarbon chain length in E. coli: inducible degradation of an essential ketoacyl synthase ${ }^{129}$, and the use of a tes $A$ mutant ${ }^{130}$ that has shifted activity toward medium-acylchain substrates. In the first strategy ${ }^{129}$, an E. coli ketoacyl synthase (encoded by $f a b F$ ) that is responsible for chain elongation was mutated to limit its activity range to make $\mathrm{C}_{8}$ acyl-ACP. Simultaneously, another ketoacyl synthase (encoded by $f a b B$ ) was engineered to be degraded on the addition of an inducer. This strategy produced approximately $260 \mathrm{mg} \mathrm{l}^{-1}$ of total FFAs in E. coli ${ }^{129}$. In the second strategy ${ }^{130}$, a mutated fatty acyl-ACP thioesterase (encoded by tes $A$ ) was expressed to favour the conversion of $\mathrm{C}_{4-12}$ fatty acyl-ACPs to FFAs, which were converted to alkanes by the sequential action of $E$. coli fatty acyl-CoA synthetase, C. acetobutylicum fatty acyl-CoA reductase and Arabidopsis thaliana fatty aldehyde decarbonylase. The final engineered E. coli strain ${ }^{130}$ produced up to $580.8 \mathrm{mg} \mathrm{l}^{-1}$ of medium-chain alkanes $\left(\mathrm{C}_{9-14}\right)$. Importantly, the production of alkanes or alkenes from highly oxygenated raw materials, such as carbohydrates, suffers from the intrinsic loss of molecular mass, which results in low theoretical yields.

Certain species of yeast, such as Yarrowia lipolytica ${ }^{131,132}$, are capable of accumulating lipids to levels in excess of $70 \%$ of their biomass. As biosynthetic enzymes that are involved in the synthesis of saturated fatty acids are subjected to feedback inhibition, one strategy to increase yields is to convert saturated fatty acids into monounsaturated fatty acids ${ }^{133}$ while sequestering pathway products in a fatty acid sink. Overexpression of acetyl-CoA carboxylase (ACC1), diacylglyceride acyl-transferase (DGA1) and $\Delta 9$ stearoyl-CoA desaturase (SCD; a regulatory enzyme that catalyses the desaturation of palmitoyl-CoA and stearoyl-CoA to palmitoleoyl-CoA and oleoyl-CoA, respectively), resulted in high lipid accumulation. The engineered strain achieved lipid titres of $55 \mathrm{~g} \mathrm{l}^{-1}$, which is $84.7 \%$ of theoretical maximum yields, with a high productivity $\left(1 \mathrm{~g} \mathrm{l}^{-1} \mathrm{~h}^{-1}\right.$ during the stationary phase). Similarly, a strain of Y. lipolytica has been engineered for fast growth and lipid overproduction by reverse engineering, based on mammalian cellular obese phenotypes ${ }^{133}$. In short, stearoyl-CoA desaturase was hypothesized to have a key regulatory role in fat accumulation, on the basis of an analysis of published mammalian transcriptome data, and the corresponding gene was overexpressed in Y. lipolytica to create the obese phenotype in yeast. In general, overcoming intricate cellular regulation has proved to be one of the major challenges in the overproduction of fatty acids ${ }^{125}$.

Isoprenoid pathways. Another route for carbon chain elongation is through the isoprenoid pathways, which increase the chain length by multiples of five through addition of the pyrophosphate-activated isopentenyl pyrophosphate (IPP) to dimethylallyl pyrophosphate (DMAPP) (FIG. 3). After chain elongation to geranyl pyrophosphate (GPP) or farnesyl pyrophosphate (FPP), the isoprenoid compounds are then modified by various terpene synthases or other enzymes to generate the final compound. IPP is produced either through the mevalonate (MVA) pathway, which exists in mammals, yeasts and plant cytosol, or the methylerythritol-4phosphate (MEP) pathway, which is found in bacteria and plant plastids ${ }^{134}$. The MVA pathway initiates from three acetyl-CoA molecules, whereas the MEP pathway begins with pyruvate and glyceraldehyde-3-phosphate. As acetyl-CoA is derived from pyruvate with a carbon loss, the MVA pathway is intrinsically less efficient than the MEP pathway in terms of carbon yield. Nonetheless, the MVA pathway from S. cerevisiae has been engineered in E. coli $i^{135,136}$ to provide dual routes to the same products. Furthermore, the overexpression of $n u d B$ (encoding a Nudix hydrolase) and nemA (encoding a reductase in the old yellow enzyme family) $)^{137}$ were used to convert the $\mathrm{C}_{5}$ intermediates IPP and DMAPP to isopentenols and isopentanol. The production of these alcohols in E. coli has been accomplished using either the MVA pathway ${ }^{138}$ or the MEP pathway ${ }^{139}$. The MVA pathway achieved yields of $2.23 \mathrm{~g} \mathrm{l}^{-1}$ of 3-methyl-3-buten-1-ol (which corresponds to approximately $70 \%$ of pathway-dependent theoretical yield), $150 \mathrm{mg} \mathrm{l}^{-1}$ of 3-methyl-2-buten-1-ol and $300 \mathrm{mg} \mathrm{l}^{-1}$ of 3-methyl-1-butanol, whereas the MEP pathway achieved approximately $60 \mathrm{mg} \mathrm{l}^{-1}$ of isopentenol. By contrast, 3-methyl-1-butanol was produced using the keto acid pathway in E. coli, yielding $4.4 \mathrm{gl}^{-1}$. A related compound, isoprene, was also produced from either cyanobacteria ${ }^{140}$ or B. subtilis ${ }^{141}$ by expressing the isoprene synthase gene (IspS) from Pueraria montana.

Pinene $\left(\mathrm{C}_{10} \mathrm{H}_{16}\right)^{142}$ has been produced in E. coli to $28 \mathrm{mg} \mathrm{l}^{-1}$ using GPP as an intermediate, by combinatorially expressing three pinene synthases and three GPP synthases (GPPSs). Pinene is of interest because pinene dimers have been shown to have a volumetric heating value similar to the jet fuel JP10 (REF. 143). Limonene $\left(\mathrm{C}_{10} \mathrm{H}_{16}\right)$ has been produced in E. coli to $400 \mathrm{mg} \mathrm{l}^{-1}$ from glucose using a heterologous MVA pathway and limonene synthase ${ }^{144}$. Limonene has also been produced in Synechococcus sp. PCC 7002 (REF. 145) to $4 \mathrm{mg} \mathrm{l}^{-1}$.

Using FPP as a starting substrate, various sesquiterpenes can be produced by expressing the corresponding sesquiterpene synthases, including amorphadiene $^{146}$, bisabolen $\mathrm{e}^{147}$ and farnesene $\mathrm{e}^{148}$. Bisabolene is a desirable product because its hydrogenated product, bisabolane, has properties similar to D2 diesel fuel ${ }^{147}$. 
Bisabolene was produced in both E. coli and S. cerevisiae to titres more than $900 \mathrm{mgl}^{-1}$ by screening for an appropriate bisabolene synthase $\mathrm{e}^{147}$. This compound was also produced in Streptomyces venezuelae $e^{149}$ and Synechococcus sp. PCC 7002 (REF. 145) to widen the host range.

Farnesene is being commercialized as a biofuel and can also be used in other applications, such as cosmetics, perfumes, detergents and industrial lubricants. Farnesene has been produced by S. cerevisiae after expressing the farnesene synthase from the plant Artemisia annua and overexpression of the native yeast enzymes of the MVA pathway ${ }^{148}$. As farnesene has a low water solubility, high-level production of this compound is well tolerated by $S$. cerevisiae. Subsequent chemical hydrogenation yields farnesane, which can act as a biodiesel ${ }^{148}$. Other attempts to increase the production of sesquiterpene include overexpression of foreign MVA pathway genes in $E$. coli ${ }^{150}$, and overexpression of the catalytic domain of 3-hydroxy-3-methylglutaryl-CoA (HMG CoA) reductase in yeast ${ }^{151}$.

\section{Optimizing biofuel production}

Because of the low unit price and extremely large quantity required for biofuels, the production of biofuel needs to be thoroughly efficient. Every opportunity to increase yield, titre and productivity needs to be explored. Almost all metabolic engineering strategies start from overexpressing the desired pathway genes, followed by knocking out competing pathways that drain precursors, products or cofactors. Creating a new pathway for precursor supply has also been shown to be useful ${ }^{135}$. Circumventing or deleting the native regulatory loops ${ }^{110,130}$ or constructing an artificial regulatory circuit $^{152,153}$ can also be beneficial, as can global mutation and selection strategies ${ }^{85,154}$.

The use of electron carriers (NADH, NADPH or reduced ferredoxin) needs to be properly balanced to streamline cofactor regeneration. For example, the change of enzyme cofactor from NADPH to NADH by an engineered enzyme enabled the anaerobic production of isobutanol at $100 \%$ theoretical yield in E. coli ${ }^{100}$. The production of 1-butanol and 1-propanol also benefited from cofactor balancing ${ }^{106,114}$, in which an NADHproducing or NADPH-producing pathway is matched by a consumption pathway using the same redox cofactor. Furthermore, in anaerobes, electron flux is often complex and undercharacterized, so understanding the electron flux in the organism in question is often the key to high-yield production ${ }^{155,156}$.

Identifying the driving force for pathway flux often leads to useful strategies for increasing production ${ }^{62,106}$. Efficient metabolic pathways need to be driven by both kinetic and thermodynamic driving forces, which can be manipulated through the size of the metabolite or cofactor pool. For example, in the CoA-dependent 1-butanol synthesis pathway, the thiolase reaction that condenses two moles of acetyl-CoA is thermodynamically unfavourable. In S. elongatus PCC 7942, this step was re-routed through malonyl-CoA ${ }^{157}$ by a decarboxylative condensation to form acetoacetyl-CoA, by overexpressing $n p h T 7$ (encoding a newly identified acetoacetyl-CoA synthase) from Streptomyces sp. In this way, one mole of ATP was invested to drive the reaction, as well as the irreversible decarboxylation.

Prolonging the production phase without cell growth is a common hallmark of successful industrial biofuel production ${ }^{6}$. Extending the working life of cells would reduce the carbon loss for cell mass production, increase the product titre and reduce the frequency of down-time between batches of cell growth. However, because of the increased titres, product toxicity becomes a determining factor of the process ${ }^{158}$. Importantly, toxicity here is defined not as toxicity to growth, but rather as toxicity to production; there are many examples of systems in which product continues to accumulate in the stationary phase $e^{98}$ to a level that is much higher than that seen during cell growth, which suggests that toxicity to production (which occurs mostly during stationary phase) would be a major problem in such systems.

Most compounds of interest start from the $\mathrm{C}_{2}$ unit acetyl-CoA in biosynthesis, with exceptions, such as isobutanol and MEP-derived isoprenoids. In most organisms, acetyl-CoA is synthesized from the $\mathrm{C}_{3}$ metabolite pyruvate through a decarboxylation step which loses one-third of the carbon. Unless the organism can fix $\mathrm{CO}_{2}$ through pathways such as the Wood-Ljungdahl pathway (BOX 3), this decarboxylation step limits the maximum theoretical carbon yield to $66.6 \%$ for any products that are derived from acetyl-CoA. The loss of carbon is a necessary result from glycolytic pathways, such as the Embden-Meyerhof-Parnas pathway (EMP pathway), which involve pyruvate as an intermediate in the partial oxidation of carbohydrates to gain reducing power and ATP. This loss of carbon substantially decreases the theoretical yield of desired metabolic products and simultaneously releases GHGs into the environment. In principle, the Wood-Ljungdahl pathway can be introduced into the producing organisms of interest to recapture the lost carbon, if additional reducing power can be supplied through either external electron sources or photosynthesis. However, technical difficulties remain to be solved before this approach can be realized. Alternatively, a non-oxidative glycolysis pathway (NOG pathway) or a reverse glyoxylate shunt (rGS) can also be used to conserve carbon ${ }^{159,160}$ (BOX 3). Indeed, the NOG pathway was engineered into E. coli and demonstrated the generation of acetyl-CoA through redox-neutral carbon rearrangement from sugars, thus boosting the theoretical yield of acetyl-CoA from two to three molecules per glucose ${ }^{159}$.

\section{Outlook}

Although not all biofuels are sustainable, replacing fossil fuels with truly sustainable biofuels is a desirable approach to ameliorating the climate change problem, but it presents daunting challenges on multiple fronts ${ }^{9,11}$. These include the efficient generation and collection of renewable resources followed by high-yield microbial conversion to desirable fuels. Every step needs to be improved to increase efficiency and reduce the direct or indirect costs to the environment and the manufacturer. These challenges are not limited to the optimization of existing technologies, but in many cases call for 
new engineering design and scientific discovery. In the short term, plant biomass seems to be the most abundant raw material and has a minimal technological barrier for commercialization. All of the processes that are required for the conversion of plant biomass are technologically feasible, albeit economically challenging. Indeed, a handful of plants producing lignocellulosic ethanol have been in operation for the past few years. Another possible raw material is methane, either from landfill or from otherwise flared natural gas. Ultimately, atmospheric $\mathrm{CO}_{2}$ should be the carbon source for fuel production. Methane or $\mathrm{CO}_{2}$ utilization by microorganisms still requires substantial scientific and technological improvement.
However, in many cases, a combination of chemical and microbial processes may present synergistic advantages, such as the production of electrofuels, or the chemical oxidation of methane to methanol followed by microbial methanol utilization.

In terms of a fuel compound, ethanol will still be the front runner in the near future, and possibly longer, because of both the ease of its production and the existing market. However, longer-chain fuels, such as isobutanol and fatty acid-derived and isoprenoid-derived fuels, are promising because of technological advances and better fuel properties. Some longer-chain biofuels can be used as, or converted to, aviation fuels $\left(\sim \mathrm{C}_{12}\right)$ or diesel $\left(\sim \mathrm{C}_{16}\right)$,

\section{Box 3 | Rewiring central metabolism to achieve total carbon conservation}

Glycolysis splits sugar to pyruvate and then to acetyl-CoA as the starting metabolite for almost all fuel compounds of interest. The conversion of pyruvate to acetyl-CoA involves decarboxylation and carbon loss in the form of $\mathrm{CO}_{2}$ or formate. This loss of carbon substantially decreases the theoretical yield of desired fuel products. To achieve total carbon conservation between glucose and acetyl-CoA molecules, three alternatives exist: the natural Wood-Ljungdahl pathway ${ }^{20}$; and two synthetic pathways, non-oxidative glycolysis (NOG) $)^{159}$ and the reverse glyoxylate shunt ( $\mathrm{rGS})^{160}$ (see the figure).

Nature's way of conserving carbon is through fixing the $\mathrm{CO}_{2}$ released in glycolysis by the Wood-Ljungdahl pathway ${ }^{20}$, which is found in acetogens and methanogens. This pathway directly fixes two $\mathrm{CO}_{2}$ molecules to synthesize acetyl-CoA. However, the pathway involves several complex enzymes that are oxygen sensitive. Therefore, engineering this pathway remains a challenge.

NOG can occur in several modes, but each mode starts from a sugar phosphate, such as fructose-6-phosphate (F6P). The input F6P is first recombined with erythrose-4-phosphate (E4P) through the action of transaldolase (Tal) and transketolase (Tkt) to generate xylulose-5phosphate (X5P), which is then cleaved by phosphoketolase (Xpk) to generate acetyl-phosphate (AcP) and glyceraldehyde-3-phosphate (G3P). The irreversible Xpk-mediated reaction also acts as a driving force for the entire pathway. The sugar phosphates in the cycle go through several steps of carbon rearrangement, similar to that found in the pentose phosphate pathway and the Calvin cycle, eventually regenerating E4P ready for the next round of conversion. The end product, AcP, can be converted to ethanol or acetate. A near stoichiometric conversion from carbohydrate to acetate through NOG has been experimentally demonstrated in vivo ${ }^{159}$.

$\mathrm{rGS}^{160}$ provides a different approach to achieve the complete carbon conservation. The overall scheme of rGS starts by converting phosphoenolpyruvate (PEP) to oxaloacetate (OAA) using PEP carboxykinase (Pck) while fixing one molecule of $\mathrm{CO}_{2}$. The resulting $\mathrm{C}_{4}$ metabolite, OAA, can be converted to two acetyl-CoA molecules through rGS and the associated reactions. Reversal of the glyoxylate shunt is made possible through an ATP-dependent malate thiokinase (Mtk) and malyl-CoA lyase $(\mathrm{Mcl})^{160}$. The other PEP generated from glucose goes through the lower part of typical glycolysis to generate another acetyl-CoA. The two parallel pathways combined can reach reducing-power neutrality with a net output of three acetyl-CoA molecules, the same as NOG.

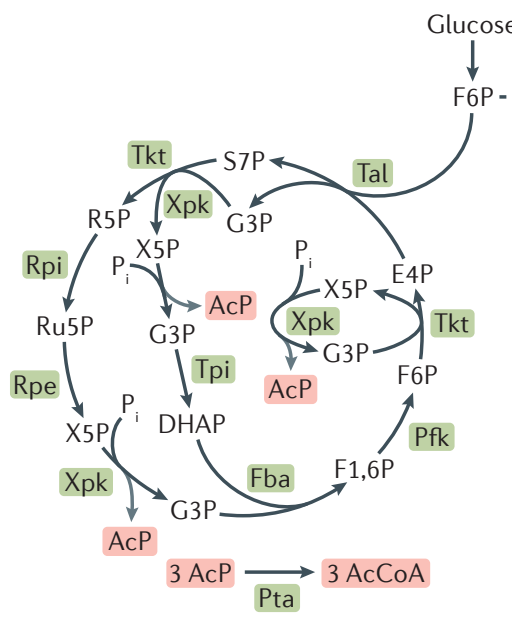

NOG
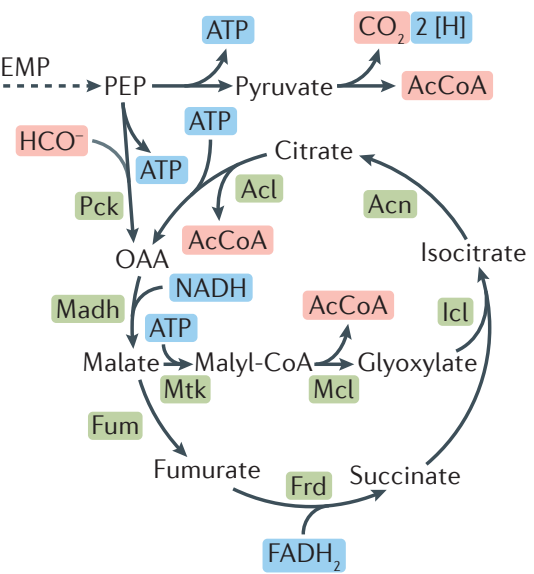

rGS

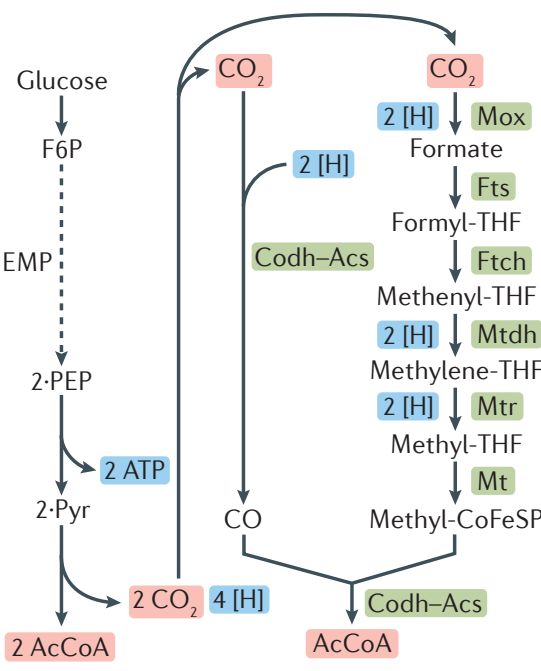

Wood-Ljundahl pathway

AcCoA, acetyl-CoA; Acl, ATP-citrate lyase; Acn, aconitase; Codh-Acs, carbon monoxide dehydrogenase-acetyl-CoA synthase; CoFeSP, corrinoid iron-sulfur protein; DHAP, dihydroxyacetone phosphate; EMP, Embden-Meyerhof-Parnas pathway; F1,6P, fructose-1,6-bisphosphate; Fba, fructose 1,6-bisphosphate (FBP) aldolase; Frd, fumarate reductase; Ftch, formyl-THF cyclohydrolase; Fts, formyl-THF synthase; Fum, fumarase; Icl, isocitrate lyase; Madh, malate dehydrogenase; Mox, methanol oxidase; Mt, methyltransferase; Mtdh, methylene-THF dehydrogenase; Mtr, methylene-THF reductase; Pfk, phosphofructokinase; $\mathrm{P}_{\mathrm{i}}$, inorganic phosphate; Pta, phosphate acetyltransferase; R5P, ribose-5-phosphate; Rpe, R5P epimerase; Rpi, R5P isomerase; Ru5P, ribulose-5-phosphate; S7P, sedoheptulose-7-phosphate;

THF, tetrahydrofolate; Tpi, triose phosphate isomerase. 
both of which have growing markets. Other fuel compounds, such as farnesene, that can act as precursors for higher-value products are also being actively pursued.

Because of advances in molecular genetics and genome-editing techniques, resource utilization and product formation can, in principle, be implemented in any microbial host of interest. When choosing the production organism, one should consider the potential to achieve the highest yield and productivity within the time frame of interest, and the robustness of the organism against environmental challenges. Although native producers typically give a better outlook initially, non-native producers often produce surprisingly well, presumably because of the lack of native regulation that restrains the pathway flux. Another factor to take into account when selecting a producing organism is that anaerobic production may preserve electrons for fuel production and save the cost of aeration, but it may also reduce the rate of production. Therefore, the cost of aeration needs to be offset by a productivity increase if aeration is needed.
Robustness against contamination by other microorganisms and phages should also be considered, as should tolerance to extreme conditions, such as high or low $\mathrm{pH}$ and temperature.

At present, it is easier to modify organisms that natively contain resource utilization pathways, such as cellulose degradation, $\mathrm{CO}_{2}$ fixation or methane oxidation, than it is to engineer production strains to carry these resource utilization pathways. However, when setting long-term goals, one should consider the theoretical limitation of the pathway design, as advances in genetic tools are likely to overcome practical difficulties and enable production to achieve the theoretical limit. Substantial room exists to improve the yield and productivity beyond the scope of natural metabolic networks. From a microbiology standpoint, the discovery and design of novel enzymes, pathways or organisms, coupled with innovative, efficient and inexpensive processing technologies, will contribute significantly to the ultimate success of sustainable biofuels.
1. Stocker, T. F. et al. in Climate Change 2013: the Physical Science Basis. Contribution of Working Group I to the Fifth Assessment Report of the Intergovernmental Panel on Climate Change (eds Stocker, T. F. et al.) 13-115 (Cambridge Univ. Press, 2013).

2. O'Neill, B. C. \& Oppenheimer, M. Dangerous climate impacts and the Kyoto Protocol. Science 296, 1971-1972 (2002).

A discussion of the potential dangerous anthropogenic effects on the climate system in three areas: severe degradation of coral ree systems, disintegration of the WAIS and shut down of the large-scale, density-driven circulation of the oceans.

3. Pacala, S. \& Socolow, R. Stabilization wedges: solving the climate problem for the next 50 years with current technologies. Science 305, 968-972 (2004). A report proposing strategies for reducing carbon emissions by $25 \mathrm{Gt}$ between 2004 and 2054 .

4. Lewis, S. N. \& Nocera, G. D. Powering the planet: chemical challenges in solar energy utilization. Proc. Natl Acad. Sci. USA 103, 15729-15735 (2006).

5. Bothast, R. J. \& Schlicher, M. A. Biotechnological processes for conversion of corn into ethanol. Appl. Microbiol. Biotechnol. 67, 19-25 (2005)

6. Basso, L. C., Basso, T. O. \& Rocha, S. N. in Biofuel Production. Recent Developments and Prospects (ed Bernardes, M. A. d. S.) 85-100 (InTech, 2011).

7. Goldemberg, J. Ethanol for a sustainable energy future. Science 315 808-810 (2009).

8. Fargione, J., Hill, J., Tilman, D., Polasky, S $\&$ Hawthorne, P. Land clearing and the biofuel carbon debt. Science 319, 1235-1238 (2008).

A paper suggesting that biofuels made from waste biomass or from biomass grown on degraded and abandoned agricultural lands incur little or no carbon debt and can offer immediate and sustained advantages relating to $\mathrm{GHGs}$.

9. Searchinger, T. D. et al. Fixing a critical climate accounting error. Science 326, 527-528 (2009). An article reporting that using biomass for energy reduces GHG emissions only if the growth and harvesting of the biomass captures carbon above and beyond the amount that would be sequestered by the same biomass.

10. Sala, O., Sax, D. \& Leslie, H. in Biofuels: Environmental Consequences \& Interactions with Changing Land Use (eds Howarth, R. W. \& Bringezu, S.) 127-137 (Cornell Univ. Press, 2008).

11. Fiorese, G., Catenacci, M., Verdolini, E. \& Bosetti, V. Advanced biofuels: future perspectives from an expert elicitation survey. Energy Policy 56, 293-311 (2013).

12. Yvon-Durocher, G. et al. Methane fluxes show consistent temperature dependence across microbial to ecosystem scales. Nature 507, 488-491 (2014).
13. Lynd, L. R., Weimer, P. J., van Zyl, W. H. \& Pretorius, I. S. Microbial cellulose utilization: fundamentals and biotechnology. Microbiol. Mol. Biol. Rev. 66, 506-577 (2002).

A comprehensive review of cellulases.

14. Rauch, R., Hrbek, J. \& Hofbauer, H. Biomass gasification for synthesis gas production and applications of the syngas. WIREs Energy Environ. 3, 343-362 (2014).

15. Holtzapple, M. \& Granda, C. Carboxylate platform: the MixAlco process part 1: comparison of three biomass conversion platforms. Appl. Biochem. Biotechnol. 156 95-106 (2009)

16. Agler, M. T., Wrenn, B. A., Zinder, S. H. \& Angenent, L. T. Waste to bioproduct conversion with undefined mixed cultures: the carboxylate platform. Trends Biotechnol. 29, 70-78 (2015).

17. Liew, L. N., Shi, J. \& Li, Y. Methane production from solid-state anaerobic digestion of lignocellulosic biomass. Biomass Bioenergy 46, 125-132 (2012)

18. Hu, J., Yu, F. \& Lu, Y. Application of Fischer-Tropsch synthesis in biomass to liquid conversion. Catalysts $\mathbf{2}$, 303 (2012).

19. Henstra, A. M., Sipma, J., Rinzema, A. \& Stams, A. J. M. Microbiology of synthesis gas fermentation for biofuel production. Curr. Opin. Biotechnol. 18, 200-206 (2007).

20. Schuchmann, K. \& Muller, V. Autotrophy at the thermodynamic limit of life: a model for energy conservation in acetogenic bacteria. Nat. Rev. Microbiol. 12, 809-821 (2014).

21. Weimer, P. J., Russell, J. B. \& Muck, R. E. Lessons from the cow: what the ruminant animal can teach us about consolidated bioprocessing of cellulosic biomass. Bioresour. Technol. 100, 5323-5331 (2009).

22. Mosier, N. et al. Features of promising technologies for pretreatment of lignocellulosic biomass. Bioresour. Technol. 96, 673-686 (2005).

23. Kumar, P., Barrett, D. M., Delwiche, M. J. \& Stroeve, P. Methods for pretreatment of lignocellulosic biomass for efficient hydrolysis and biofuel production. Ind. Eng. Chem Res. 48, 3713-3729 (2009).

24. Martinez, D. et al. Genome sequencing and analysis of the biomass-degrading fungus Trichoderma reesei (syn Hypocrea jecorina). Nat. Biotechnol. 26, 553-560 (2008).

25. Cherry, J. R. \& Fidantsef, A. L. Directed evolution of industrial enzymes: an update. Curr. Opin. Biotechnol. 14, 438-443 (2003)

26. Van Tilbeurgh, H., Tomme, P., Claeyssens, M., Bhikhabhai, R. \& Pettersson, G. Limited proteolysis of the cellobiohydrolase I from Trichoderma reesei: separation of functional domains. FEBS Lett. 204 223-227 (1986).

27. Henrissat, B. Cellulases and their interaction with cellulose. Cellulose 1, 169-196 (1994).

28. Väljamäe, P., Sild, V., Nutt, A., Pettersson, G. $\&$ Johansson, G. Acid hydrolysis of bacterial cellulose reveals different modes of synergistic action between cellobiohydrolase I and endoglucanase I. Eur. J. Biochem. 266, 327-334 (1999).

29. Heinzelman, P. et al. Efficient screening of fungal cellobiohydrolase class I enzymes for thermostabilizing sequence blocks by SCHEMA structure-guided recombination. Protein Eng. Des. Sel. 23, 871-880 (2010).

30. Wu, I. \& Arnold, F. H. Engineered thermostable fungal Cel6A and Cel7A cellobiohydrolases hydrolyze cellulose efficiently at elevated temperatures. Biotechnol. Bioeng. 110, 1874-1883 (2013).

31. Liu, G., Zhang, J. \& Bao, J. Cost evaluation of cellulase enzyme for industrial-scale cellulosic ethanol production based on rigorous Aspen Plus modeling. Bioprocess Biosyst. Eng. 39, 133-140 (2016).

32. Klein-Marcuschamer, D., Oleskowicz-Popiel, P., Simmons, B. A. \& Blanch, H. W. The challenge of enzyme cost in the production of lignocellulosic biofuels. Biotechnol. Bioeng. 109, 1083-1087 (2012).

33. Gusakov, A. V. Alternatives to Trichoderma reesei in biofuel production. Trends Biotechnol. 29, 419-425 (2011).

34. Bayer, E. A., Kenig, R. \& Lamed, R. Adherence of Clostridium thermocellum to cellulose. J. Bacteriol. 156, 818-827 (1983).

35. Lu, Y., Zhang, Y.-H. P. \& Lynd, L. R. Enzyme-microbe synergy during cellulose hydrolysis by Clostridium thermocellum. Proc. Natl Acad. Sci. USA 103, 16165-16169 (2006)

36. You, C., Zhang, X.-Z., Sathitsuksanoh, N., Lynd, L. R. $\&$ Zhang, Y.-H. P. Enhanced microbial utilization of recalcitrant cellulose by an ex vivo cellulosomemicrobe complex. Appl. Environ. Microbiol. 78, 1437-1444 (2012).

37. Gerngross, U. T., Romaniec, M. P., Kobayashi, T., Huskisson, N. S. \& Demain, A. L. Sequencing of a Clostridium thermocellum gene (cipA) encoding the cellulosomal $\mathrm{S}$-protein reveals an unusual degree of internal homology. Mol. Microbiol. 8, 325-334 (1993).

38. Schwarz, W. H. The cellulosome and cellulose degradation by anaerobic bacteria. Appl. Microbiol. Biotechnol. 56, 634-649 (2001).

39. Zhang, Y.-H. P. \& Lynd, L. R. Cellulose utilization by Clostridium thermocellum: bioenergetics and hydrolysis product assimilation. Proc. Natl. Acad. Sci. USA 102, 7321-7325 (2005)

The demonstration that there is an advantage to the uptake of cellodextrins with $4-5$ sugar units in C. thermocellum.

40. Zhang, Y.-H. P. \& Lynd, L. R. Kinetics and relative importance of phosphorolytic and hydrolytic cleavage of cellodextrins and cellobiose in cell extracts of Clostridium thermocellum. Appl. Environ. Microbiol. 70, 1563-1569 (2004). 
41. Resch, M. G. et al. Fungal cellulases and complexed cellulosomal enzymes exhibit synergistic mechanisms in cellulose deconstruction. Energy Environ. Sci. 6, 1858-1867 (2013).

42. Resch, M. G. et al. Clean fractionation pretreatment reduces enzyme loadings for biomass saccharification and reveals the mechanism of free and cellulosomal enzyme synergy. ACS Sustainable Chem. Eng. 2, 1377-1387 (2014).

43. Lochner, A. et al. Use of label-free quantitative proteomics to distinguish the secreted cellulolytic systems of Caldicellulosiruptor bescii and Caldicellulosiruptor obsidiansis. Appl. Environ. Microbiol. 77, 4042-4054 (2011).

44. Brunecky, R. et al. Revealing nature's cellulase diversity: the digestion mechanism of Caldicellulosiruptor bescii CelA. Science 342, 1513-1516 (2013)

45. Shallom, D. \& Shoham, Y. Microbial hemicellulases. Curr. Opin. Microbiol. 6, 219-228 (2003).

46. Demain, A. L. et al. Cellulase, clostridia, and ethanol Microbiol. Mol. Biol. Rev. 69, 124-154 (2005). An overview of the structure and function of the C. thermocellum cellulosome, including a historical perspective of the early research efforts on the subject.

47. Hahn-Hägerdal, B., Karhumaa, K., Fonseca, C. Spencer-Martins, I. \& Gorwa-Grauslund, M. F. Towards industrial pentose-fermenting yeast strains. Appl. Microbiol. Biotechnol. 74, 937-953 (2007).

48. Kuyper, M. et al. Metabolic engineering of a xyloseisomerase-expressing Saccharomyces cerevisiae strain for rapid anaerobic xylose fermentation. FEMS Yeast Res. 5, 399-409 (2005).

49. Mohagheghi, A. et al. Improving xylose utilization by recombinant Zymomonas mobilis strain 8b through adaptation using 2-deoxyglucose. Biotechnol. Biofuels 7, 19 (2014)

50. Farwick, A., Bruder, S., Schadeweg, V., Oreb, M. $\&$ Boles, E. Engineering of yeast hexose transporters to transport D-xylose without inhibition by $\mathrm{D}$-glucose. Proc. Natl Acad. Sci. USA 111, 5159-5164 (2014).

51. Azadi, P., Inderwildi, O. R., Farnood, R. \& King, D. A. Liquid fuels, hydrogen and chemicals from lignin: A critical review. Renew. Sust. Energ. Rev. 21, 506-523 (2002).

52. Ragauskas, A. J. et al. Lignin valorization: improving lignin processing in the biorefinery. Science 344 1246843 (2014)

A comprehensive review of lignin characterization and refinement, and the future potential for lignin valorization.

53. Martínez, Á. T. et al. Biodegradation of lignocellulosics: microbial, chemical, and enzymatic aspects of the fungal attack of lignin. Int. Microbiol. 8, 195-204 (2005).

54. Haider, K., Trojanowski, J. \& Sundman, V. Screening for lignin degrading bacteria by means of ${ }^{14} \mathrm{C}$-labelled lignins. Methods 119, 103-106 (1978).

55. Fuchs, G., Boll, M. \& Heider, J. Microbial degradation of aromatic compounds - from one strategy to four. Nat. Rev. Microbiol. 9, 803-816 (2011)

56. Johnson, C. W. \& Beckham, G. T. Aromatic catabolic pathway selection for optimal production of pyruvate and lactate from lignin. Metab. Eng. 28, 240-247 (2015).

57. Chisti, Y. Biodiesel from microalgae. Biotechnol. Adv 25, 294-306 (2007)

\section{A summary of the technical and economical} feasibility of microalga-derived biodiesel.

58. Rodolfi, L. et al. Microalgae for oil: strain selection, induction of lipid synthesis and outdoor mass cultivation in a low-cost photobioreactor. Biotechnol. Bioeng. 102, 100-112 (2009).

59. Boyle, N. R. et al. Three acyltransferases and nitrogenresponsive regulator are implicated in nitrogen starvation-induced triacylglycerol accumulation in Chlamydomonas. J. Biol. Chem. 287, 15811-15825 (2012).

60. Cerutti, H., Ma, X., Msanne, J. \& Repas, T. RNA mediated silencing in algae: biological roles and tools for analysis of gene function. Eukaryot. Cell 10 1164-1172 (2011).

61. Gimpel, J. A., Specht, E. A., Georgianna, D. R. $\&$ Mayfield, S. P. Advances in microalgae engineering and synthetic biology applications for biofuel production. Curr. Opin. Chem. Biol. 17, 489-495 (2013).

A report concerning recent advances in the genetic manipulation of microalgae.
62. Angermayr, S. A., Gorchs Rovira, A. \& Hellingwerf, K. J. Metabolic engineering of cyanobacteria for the synthesis of commodity products. Trends Biotechnol. 33, 352-361 (2015)

63. Korczynski, P. C., Logan, J. \& Faust, J. E. Mapping monthly distribution of daily light integrals across the contiguous United States. HortTechnology 12, 12-16 (2002)

64. Chen, C. Y., Yeh, K. L., Aisyah, R., Lee, D. J. \& Chang, J. S. Cultivation, photobioreactor design and harvesting of microalgae for biodiesel production: a critical review. Bioresour. Technol. 102, 71-81 (2011).

65. Hannon, M., Gimpel, J., Tran, M., Rasala, B. \& Mayfield, S. Biofuels from algae: challenges and potential. Biofuels 1, 763-784 (2010).

66. Zhu, X. G., Long, S. P. \& Ort, D. R. What is the maximum efficiency with which photosynthesis can convert solar energy into biomass? Curr. Opin. Biotechnol. 19, 153-159 (2008).

67. Ludwig, M. \& Bryant, D. A. Synechococcus sp. strain PCC 7002 transcriptome: acclimation to temperature, salinity, oxidative stress, and mixotrophic growth conditions. Front. Microbiol. 3, 354 (2012).

68. Conrado, R., Haynes, C., Haendler, B. \& Toone, E. in Advanced Biofuels and Bioproducts (ed. Lee, J. W.) 1037-1064 (Springer, 2013).

69. Blankenship, R. E. et al. Comparing photosynthetic and photovoltaic efficiencies and recognizing the potentia for improvement. Science 332, 805-809 (2011).

70. Luo, X., Wang, J., Dooner, M. \& Clarke, J. Overview of current development in electrical energy storage technologies and the application potential in powe system operation. Appl. Energy 137, 511-536 (2015).

71. Li, H. et al. Integrated electromicrobial conversion of $\mathrm{CO}_{2}$ to higher alcohols. Science 335, 1596-1596 (2012)

A paper reporting the creation of an integrated electromicrobial process for electricity-driven $\mathrm{CO}_{2}$ conversion to higher alcohols using genetically engineered $C$. necator $\mathrm{H} 16$.

72. Torella, J. P. et al. Efficient solar-to-fuels production from a hybrid microbial-water-splitting catalyst system. Proc. Natl Acad. Sci. USA 112, 2337-2342 (2015).

73. Grousseau, E., Lu, J., Gorret, N., Guillouet, S. E. $\&$ Sinskey, A. J. Isopropanol production with engineered Cupriavidus necator as bioproduction platform. Appl. Microbiol. Biotechnol. 98, 4277-4290 (2014)

74. Keller, M. W. et al. Exploiting microbial hyperthermophilicity to produce an industrial chemical using hydrogen and carbon dioxide. Proc. Natl Acad. Sci. USA 110, 5840-5845 (2013).

75. Gregory, K. B., Bond, D. R. \& Lovley, D. R. Graphite electrodes as electron donors for anaerobic respiration. Environ. Microbiol. 6, 596-604 (2004).

76. Nevin, K. P., Woodard, T. L. \& Franks, A. E. Microbia electrosynthesis: feeding microbes electricity to convert carbon dioxide and water to multicarbon extracellular organic compounds. mBio 1, e00103-10 (2010)

77. Nevin, K. P. et al. Electrosynthesis of organic compounds from carbon dioxide is catalyzed by a diversity of acetogenic microorganisms. Appl. Environ Microbiol. 77, 2882-2886 (2011).

78. Cicerone, R. J. \& Oremland, R. S. Biogeochemical aspects of atmospheric methane. Global Biogeochem. Cycles 2, 299 (1988)

79. Conrado, R. J. \& Gonzalez, R. Envisioning the bioconversion of methane to liquid fuels. Science 343, 621-623 (2014) An article identifying the main challenges in the utilization of methane as a feedstock for bioconversion to liquid biofuels, and discussing how these challenges might be addressed.

80. Fuerst, J. (ed.) Planctomycetes: Cell Structure, Origins and Biology (Humana Press, 2013).

81. Banerjee, R., Proshlyakov, Y., Lipscomb, J. D. $\&$ Proshlyakov, D. A. Structure of the key species in the enzymatic oxidation of methane to methanol. Nature 518, 431-434 (2015).

82. Bogorad, I. W. et al. Building carbon-carbon bonds using a biocatalytic methanol condensation cycle. Proc. Natl Acad. Sci. USA 111, 15928-15933 (2014) A report describing the design and construction of a methanol condensation cycle capable of converting methanol to higher-chain alcohols with complete carbon conservation and ATP independence.
83. Kalyuzhnaya, M. G., Puri, A. W. \& Lidstrom, M. E. Metabolic engineering in methanotrophic bacteria Metab. Eng. 29, 142-152 (2015).

84. Lam, F., Ghaderi, A., Fink, G. \& Stephanopoulos, G. Engineering alcohol tolerance in yeast. Science 346 , 71-75 (2014)

85. Caspeta, L. et al. Altered sterol composition renders yeast thermotolerant. Science 346, 75-78 (2014).

86. Hasunuma, T. et al. Metabolic pathway engineering based on metabolomics confers acetic and formic acid tolerance to a recombinant xylose-fermenting strain of Saccharomyces cerevisiae. Microb. Cell Fact. 10, 2 (2011).

87. Swings, J. \& De Ley, J. The biology of Zymomonas. Bacteriol. Rev. 41, 1-46 (1977).

88. Kremer, T. A., LaSarre, B., Posto, A. L. $\&$ McKinlay, J. B. $N_{2}$ gas is an effective fertilizer for bioethanol production by Zymomonas mobilis. Proc. Natl Acad. Sci. USA 112, 2222-2226 (2015).

89. Lynd, L. R., Van Zyl, W. H., McBride, J. E. \& Laser, M Consolidated bioprocessing of cellulosic biomass: an update. Curr. Opin. Biotechnol. 16, 577-583 (2005).

90. Zhou, J. et al. Atypical glycolysis in Clostridium thermocellum. Appl. Environ. Microbiol. 79, 3000-3008 (2013)

91. Buckel, W. \& Thauer, R. K. Energy conservation via electron bifurcating ferredoxin reduction and proton/ $\mathrm{Na}^{+}$translocating ferredoxin oxidation. Biochim. Biophys. Acta. 1827, 94-113 (2013).

92. Papanek, B., Biswas, R., Rydzak, T. \& Guss, A. M. Elimination of metabolic pathways to all traditional fermentation products increases ethanol yields in Clostridium thermocellum. Metab. Eng. 32, 49-54 (2015).

93. Dam, P. et al. Insights into plant biomass conversion from the genome of the anaerobic thermophilic bacterium Caldicellulosiruptor bescii DSM 6725. Nucleic Acids Res. 39, 3240-3254 (2011).

94. Chung, D., Cha, M., Guss, A. M. \& Westpheling, J. Direct conversion of plant biomass to ethanol by engineered Caldicellulosiruptor bescii. Proc. Natl Acad. Sci. USA 111, 8931-8936 (2014).

95. Huang, J. et al. Direct ethanol production from lignocellulosic sugars and sugarcane bagasse by a recombinant Trichoderma reesei strain HJ48. ScientificWorldJournal 2014, 798683 (2014).

96. Yamada, R. et al. Cocktail $\delta$-integration: a novel method to construct cellulolytic enzyme expression ratio-optimized yeast strains. Microb. Cell Fact. 9, 32 (2010).

97. Tsai, S. L., Oh, J., Singh, S., Chen, R. \& Chen, W. Functional assembly of minicellulosomes on the Saccharomyces cerevisiae cell surface for cellulose hydrolysis and ethanol production. Appl. Environ. Microbiol. 75, 6087-6093 (2009).

98. Atsumi, S., Hanai, T. \& Liao, J. C. Non-fermentative pathways for synthesis of branched-chain higher alcohols as biofuels. Nature 451, 86-89 (2008). The demonstration that the keto acid pathway can be used to generate $C_{4}$ and $C_{5}$ alcohols for use as biofuels, and the production of more than $20 \mathrm{~g} \mathrm{I}^{-1}$ isobutanol using $E$. coli.

99. Hazelwood, L. A., Daran, J. M., van Maris, A. J. Pronk, J. T. \& Dickinson, J. R. The Ehrlich pathway for fusel alcohol production: a century of research on Saccharomyces cerevisiae metabolism. Appl. Environ. Microbiol 74, 2259-2266 (2008).

100. Bastian, S. et al. Engineered ketol-acid reductoisomerase and alcohol dehydrogenase enable anaerobic 2-methylpropan-1-ol production at theoretical yield in Escherichia coli. Metab. Eng. 13 345-352 (2011).

101. Matsuda, F. et al. Increased isobutanol production in Saccharomyces cerevisiae by eliminating competing pathways and resolving cofactor imbalance. Microb. Cell Fact. 12, 119 (2013).

102. Li, S., Wen, J. \& Jia, X. Engineering Bacillus subtilis for isobutanol production by heterologous Ehrlich pathway construction and the biosynthetic 2-ketoisovalerate precursor pathway overexpression. Appl. Microbiol. Biotechnol. 91, 577-589 (2011).

103. Lin, P. P. et al. Consolidated bioprocessing of cellulose to isobutanol using Clostridium thermocellum. Metab. Eng. 31, 44-52 (2015)

104. Desai, S. H., Rabinovitch-Deere, C. A., Tashiro, Y \& Atsumi, S. Isobutanol production from cellobiose in Escherichia coli. Appl. Microbiol. Biotechnol. 98 3727-3736 (2014). 
105. Rodriguez, G. M., Tashiro, Y. \& Atsumi, S. Expanding ester biosynthesis in Escherichia coli. Nat. Chem. Biol. 10, 259-265 (2014).

106. Shen, C. R. et al. Driving forces enable high-titer anaerobic 1-butanol synthesis in Escherichia coli. Appl. Environ. Microbiol. 77, 2905-2915 (2011).

107. Dellomonaco, C., Clomburg, J. M., Miller, E. N. $\&$ Gonzalez, R. Engineered reversal of the $\beta$-oxidation cycle for the synthesis of fuels and chemicals. Nature 476, 355-359 (2011).

A study using a functional reversal of the $\beta$-oxidation pathway for the synthesis of longer-chain alcohols and carboxylic acids in $E$. coli.

108. Inokuma, K., Liao, J. C., Okamoto, M. \& Hanai, T. Improvement of isopropanol production by metabolically engineered Escherichia coli using gas stripping. J. Biosci. Bioeng. 110, 696-701 (2010)

109. Steen, E. J. et al. Metabolic engineering of Saccharomyces cerevisiae for the production of n-butanol. Microb. Cell Fact. 7, 36 (2008)

110. Nielsen, D. R. et al. Engineering alternative butanol production platforms in heterologous bacteria Metab. Eng. 11, 262-273 (2009).

111. Lan, E. I., Ro, S. Y. \& Liao, J. C. Oxygen-tolerant coenzyme A-acylating aldehyde dehydrogenase facilitates efficient photosynthetic $n$-butanol biosynthesis in cyanobacteria. Energy Environ. Sci. 6 , 2672 (2013).

112. Ingram, L. O., Chevalier, L. S., Gabba, E. J., Ley, K. D \& Winters, K. Propionate-induced synthesis of oddchain-length fatty acids by Escherichia coli. J. Bacteriol. 131, 1023-1025 (1977).

113. Tseng, H.-C. \& Prather, K. L. J. Controlled biosynthesis of odd-chain fuels and chemicals via engineered modular metabolic pathways. Proc. Natl Acad. Sci. USA 109, 17925-17930 (2012).

114. Shen, C. R. \& Liao, J. C. Synergy as design principle for metabolic engineering of 1-propanol production in Escherichia coli. Metab. Eng. 17, 12-22 (2013).

115. Volker, A. R. et al. Fermentative production of short chain fatty acids in Escherichia coli. Microbiology 160, 1513-1522 (2014)

116. Cornillot, E., Nair, R. V., Papoutsakis, E. T. $\&$ Soucaille, P. The genes for butanol and acetone formation in Clostridium acetobutylicum ATCC 824 reside on a large plasmid whose loss leads to degeneration of the strain. J. Bacteriol 179, 5442-5447 (1997).

117. Anbarasan, P. et al. Integration of chemical catalysis with extractive fermentation to produce fuels. Nature 491, 235-239 (2012).

118. Bond-Watts, B. B., Bellerose, R. J. \& Chang, M. C. Y Enzyme mechanism as a kinetic control element for designing synthetic biofuel pathways. Nat. Chem. Biol. 7, 222-227 (2011)

119. Saini, M., Wang, Z. W., Chiang, C.-J. \& Chao, Y.-P. Metabolic engineering of Escherichia coli for production of butyric acid. J. Agr. Food Chem. 62 4342-4348 (2014).

120. Cheon, Y. et al. A biosynthetic pathway for hexanoic acid production in Kluyveromyces marxianus. J. Biotechnol. 182-183, 30-36 (2014).

121. Black, P. N. \& DiRusso, C. C. Yeast acyl-CoA synthetases at the crossroads of fatty acid metabolism and regulation. Biochim. Biophys. Acta. 1771, 286-298 (2007)

122. Steen, E. J. et al. Microbial production of fatty-acidderived fuels and chemicals from plant biomass. Nature 463, 559-562 (2010). A paper detailing the engineering of $E$. coli to produce fatty esters, fatty alcohols and waxes directly from simple sugars, and engineering of the biodiesel-producing cells to express hemicellulases.

123. Cho, H. \& Cronan, J. E. Defective export of a periplasmic enzyme disrupts regulation of fatty acid synthesis. J. Biol. Chem. 270, 4216-4219 (1995).

124. Lu, X., Vora, H. \& Khosla, C. Overproduction of free fatty acids in $E$. coli: implications for biodiesel production. Metab. Eng. 10, 333-339 (2008)

125. Handke, P., Lynch, S. A. \& Gill, R. T. Application and engineering of fatty acid biosynthesis in Escherichia coli for advanced fuels and chemicals. Metab. Eng. 13 28-37 (2011).

126. Jiang, P. \& Cronan, J. E. Inhibition of fatty acid synthesis in Escherichia coli in the absence of phospholipid synthesis and release of inhibition by thioesterase action. J. Bacteriol. 176, 2814-2821 (1994).
127. Schirmer, A., Rude, M. A., Li, X., Popova, E. \& del Cardayre, S. B. Microbial biosynthesis of alkanes. Science 329, 559-562 (2010).

A report describing the alkane-producing pathway in cyanobacteria, including an acyl-ACP reductase and an aldehyde decarbonylase, which together convert fatty acyl-ACP to alkanes and alkenes. When introduced into $E$. coli, these two genes enable the cell to produce alkanes and alkenes.

128. Howard, T. P. et al. Synthesis of customized petroleumreplica fuel molecules by targeted modification of free fatty acid pools in Escherichia coli. Proc. Natl Acad. Sci. USA 110, 7636-7641 (2013)

129. Torella, J. P. et al. Tailored fatty acid synthesis via dynamic control of fatty acid elongation. Proc. Natl Acad. Sci. USA 110, 11290-11295 (2013).

130. Choi, Y. J. \& Lee, S. Y. Microbial production of short-chain alkanes. Nature 502, 571-574 (2013).

131. Beopoulos, A. et al. Yarrowia lipolytica as a model for bio-oil production. Prog. Lipid Res. 48, 375-387 (2009)

132. Tai, M. \& Stephanopoulos, G. Engineering the push and pull of lipid biosynthesis in oleaginous yeast Yarrowia lipolytica for biofuel production. Metab. Eng. 15, 1-9 (2013).

133. Qiao, K. et al. Engineering lipid overproduction in the oleaginous yeast Yarrowia lipolytica. Metab. Eng. 29. 56-65 (2015).

134. Kuzuyama, T. Mevalonate and nonmevalonate pathways for the biosynthesis of isoprene units. Biosci. Biotechnol. Biochem. 66, 1619-1627 (2002).

135. Martin, V. J. J., Pitera, D. J., Withers, S. T., Newman, J. D. \& Keasling, J. D. Engineering a mevalonate pathway in Escherichia coli for production of terpenoids. Nat. Biotechnol. 21, 796-802 (2003)

An investigation in which $E$. coli is engineered to express a synthetic amorpha-4,11-diene synthase gene and the mevalonate isoprenoid pathway from S. cerevisiae.

136. Jakočiūnas, T. et al. Multiplex metabolic pathway engineering using CRISPR/Cas9 in Saccharomyces cerevisiae. Metab. Eng. 28, 213-222 (2015).

137. Chou, H. H. \& Keasling, J. D. Synthetic pathway for production of five-carbon alcohols from isopentenyl diphosphate. Appl. Environ. Microbiol. 78, 7849-7855 (2012)

138. George, K. W. et al. Metabolic engineering for the high-yield production of isoprenoid-based $\mathrm{C}_{5}$ alcohols in E. coli. Sci. Rep. 5, 11128 (2015).

139. Liu, H. et al. MEP pathway-mediated isopentenol production in metabolically engineered Escherichia coli. Microb. Cell Fact. 13, 135 (2014).

140. Lindberg, P., Park, S. \& Melis, A. Engineering a platform for photosynthetic isoprene production in cyanobacteria, using Synechocystis as the model organism. Metab. Eng. 12, 70-79 (2010).

141. Xue, J. \& Ahring, B. K. Enhancing isoprene production by genetic modification of the 1-deoxy-D-xylulose5-phosphate pathway in Bacillus subtilis. Appl. Environ. Microbiol. 77, 2399-2405 (2011).

142. Sarria, S., Wong, B., Martín, H. G., Keasling, J. D. $\&$ Peralta-Yahya, P. Microbial synthesis of pinene. ACS Synth. Biol. 3, 466-475 (2014).

143. Harvey, B. G., Wright, M. E. \& Quintana, R. L. High-density renewable fuels based on the selective dimerization of pinenes. Energy Fuels 24, 267-273 (2010).

144. Alonso-Gutierrez, J. et al. Metabolic engineering of Escherichia coli for limonene and perillyl alcohol production. Metab. Eng. 19, 33-41 (2013).

145. Davies, F. K., Work, V. H., Beliaev, A. S $\S$ Posewitz, M. C. Engineering limonene and bisabolene production in wild type and a glycogen-deficient mutant of Synechococcus sp. PCC 7002. Front. Bioeng. Biotechnol. 2, 21 (2014)

146. Anthony, J. R. et al. Optimization of the mevalonate-based isoprenoid biosynthetic pathway in Escherichia coli for production of the anti-malarial drug precursor amorpha-4,11-diene. Metab. Eng. 11, $13-19$ (2009)

147. Peralta-Yahya, P. P. et al. Identification and microbial production of a terpene-based advanced biofuel. Nat. Commun. 2, 483 (2011).
148. Chandran, S. S., Kealey, J. T. \& Reeves, C. D. Microbial production of isoprenoids. Process Biochem. 46, 1703-1710 (2011). A review of isoprenoid-derived products, their biosynthetic pathways and the means by which their production can be improved.

149. Phelan, R. M., Sekurova, O. N., Keasling, J. D $\&$ Zotchev, S. B. Engineering terpene biosynthesis in Streptomyces for production of the advanced biofuel precursor bisabolene. ACS Synth. Biol. 4, 393-399 (2014).

150. Wang, C. et al. Farnesol production from Escherichia coli by harnessing the exogenous mevalonate pathway. Biotechnol. Bioeng. 107 421-429 (2010).

151. Asadollahi, M. A., Maury, J., Schalk, M., Clark, A \& Nielsen, J. Enhancement of farnesyl diphosphate pool as direct precursor of sesquiterpenes through metabolic engineering of the mevalonate pathway in Saccharomyces cerevisiae. Biotechnol. Bioeng. 106, 86-96 (2010).

152. Farmer, W. R. \& Liao, J. C. Improving lycopene production in Escherichia coli by engineering metabolic control. Nat. Biotechnol. 18, 533-537 (2000).

153. Zhang, F., Carothers, J. M. \& Keasling, J. D. Design of a dynamic sensor-regulator system for production of chemicals and fuels derived from fatty acids. Nat. Biotechnol. 30, 354-359 (2012).

154. Alper, H., Moxley, J., Nevoigt, E., Fink, G. R. $\&$ Stephanopoulos, G. Engineering yeas transcription machinery for improved ethanol tolerance and production. Science 314, 1565-1568 (2006).

A report detailing how the mutation of a global transcription factor, Spt15p, in yeast leads to increased tolerance and more efficient glucose conversion to ethanol.

155. Lo, J. et al. Deletion of $n f n A B$ in Thermoanaerobacterium saccharolyticum and its effect on metabolism. J. Bacteriol. 197, 2920-2929 (2015).

156. Biswas, R., Wilson, C. M., Zheng, T., Giannone, R. J. $\&$ Dawn, M. Elimination of hydrogenase active site assembly blocks $\mathrm{H}_{2}$ production and increases ethanol yield in Clostridium thermocellum. Biotechnol. Biofuels 8, 20 (2015).

157. Lan, E. I. \& Liao, J. C. ATP drives direct photosynthetic production of 1-butanol in cyanobacteria. Proc. Natl Acad. Sci. USA 109 6018-6023 (2012).

158. Royce, L., Liu, P., Stebbins, M., Hanson, B. \& Jarboe, L. The damaging effects of short chain fatty acids on Escherichia coli membranes. Appl. Microbiol. Biotechnol. 97, 8317-8327 (2013).

159. Bogorad, I. W., Lin, T.-S. \& Liao, J. C. Synthetic non-oxidative glycolysis enables complete carbon conservation. Nature 502, 693-697 (2013). Work demonstrating a total carbon conservation from glucose to acetyl-CoA through the redesigning of glycolysis to a NOG pathway. Instead of pyruvate oxidation, acetyl-CoA is produced by acetyl phosphate phosphoketolase as a key pathway enzyme, and sugar phosphates are carbon rearranged to achieve $100 \%$ carbon conservation.

160. Mainguet, S. E., Gronenberg, L. S., Wong, S. S. ¿ Liao, J. C. A reverse glyoxylate shunt to build a non-native route from $\mathrm{C}_{4}$ to $\mathrm{C}_{2}$ in Escherichia coli. Metab. Eng. 19, 116-127 (2013).

161. Lewis, N. S. Crabtree, G., Nozik, A. J. Wasielewski, M. R. \& Alivisatos, P. Basic research needs for solar energy utilization. US Department of Energy [online] http://science.energy.gov/ /media/bes/ pdf/reports/files/seu rpt.pdf (2005).

162. Tarascon, J.M \& Armand, M. Issues and challenges facing rechargeable lithium batteries. Nature $\mathbf{4 1 4}$ 359-367 (2001)

163. Thackeray, M. M., Wolverton, C. \& Isaacs, E. D. Electrical energy storage for transportationapproaching the limits of, and going beyond, lithium ion batteries. Energy Environ. Sci. 5, 7854 (2012).

164. Rohan, J. F., Hasan, M., Patil, S., Casey, D. P. $\&$ Clancy, T. Energy storage: battery materials and architectures at the nanoscale. ICT - Energy Concepts Towards Zero - Power Information and Communication Technology [online], http:// www.intechopen.com/books/ict-energy-conceptstowards-zero-power-information-and-communicationtechnology/energy-storage-battery-materials-andarchitectures-at-the-nanoscale (2014). 


\section{REVIEWS}

165. Ellingsen, L. A.-W. et al. Life cycle assessment of a lithium-ion battery vehicle pack. J. Ind. Ecol. 18 113-124 (2014)

166. Beer, C. et al. Terrestrial gross carbon dioxide uptake: global distribution and covariation with climate. Science 329, 834-838 (2010).

167. US Department of Energy. Billion-ton update: biomass supply for a bioenergy $\&$ bioproduct industry. US Department of Energy [online] https: www1.eere.energy.gov/bioenergy/pdfs/billion ton update.pdf (2011).

168. Salisbury, S. A., Forrest, H. S., Cruse, W. B. T. $\&$ Kennard, O. A novel coenzyme from bacterial primary alcohol dehydrogenases. Nature 280, 843-844 (1979).
169. Arfman, N. et al. Methanol metabolism in thermotolerant methylotrophic Bacillus strains involving a novel catabolic NAD-dependent methanol dehydrogenase as a key enzyme. Arch. Microbiol. 152, 280-288 (1989).

170. Baratti, J., Couderc, R., Cooney, C. L. \& Wang, D. I. C. Preparation and properties of immobilized methanol oxidase. Biotechnol. Bioeng. 20, 333-348 (1978).

171. Anthony, C. How half a century of research was required to understand bacterial growth on $\mathrm{C}_{1}$ and $\mathrm{C}_{2}$ compounds; the story of the serine cycle and the ethylmalonyl-CoA pathway. Sci. Prog. 94, 109 (2011)

172. Kalyuzhnaya, M. G. et al. Highly efficient methane biocatalysis revealed in a methanotrophic bacterium Nat. Commun. 4, 2785 (2013).
173. Culpepper, M. A. \& Rosenzweig, A. C. Architecture and active site of particulate methane monooxygenase. Crit. Rev. Biochem. Mol. Biol. 47, 483-492 (2012).

\section{Acknowledgements}

The authors appreciate support from the US Department of Energy (DOE) BioEnergy Science Center, the University of California, Los Angeles (UCLA)-DOE Institute of Genomics and Proteomics, the DOE (grant DE-SC0012384), the US National Science Foundation (grant MCB-1139318) and the DOE Advanced Research Project Agency-energy REMOTE programme.

\section{Competing interests statement}

The authors declare competing interests: see Web version for details. 